\title{
Effects of temperature on the $\beta$-phase depletion in MCrAIYs: A modelling and experimental study towards designing new bond coat alloys
}

\author{
H. Chen ${ }^{\mathrm{a}, *}$, A. Rushworth ${ }^{\mathrm{a}}$, X. Hou ${ }^{\mathrm{b}}, \mathrm{J}^{\mathrm{H}} \mathrm{He}^{\mathrm{c}}$ and H. Guo ${ }^{\mathrm{c}, *}$ \\ ${ }^{a}$ Department of Mechanical, Materials and Manufacturing Engineering, Faculty of \\ Science and Engineering, University of Nottingham Ningbo China, Ningbo 315100, \\ China \\ ${ }^{b}$ Advanced Materials Research Group, Faculty of Engineering, University of \\ Nottingham, Nottingham NG7 2RD, UK

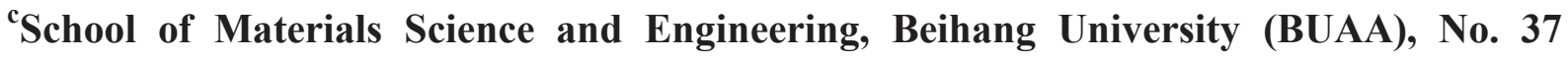 \\ Xueyuan Road, Beijing, China
}

\begin{abstract}
This paper investigates the effects of varied temperature conditions on the kinetics of $\beta$-phase depletion in MCrAlYs by DICTRA diffusion simulations and experimental observations. A commercially available MCrAlY composition and two modelled compositions were examined at temperature regimes of $1000{ }^{\circ} \mathrm{C}, 1100{ }^{\circ} \mathrm{C}$ and $1200{ }^{\circ} \mathrm{C}$. A previously developed temperature-dependent oxidation model was used at the boundary to examine the $\beta$-phase depletion kinetics at different temperatures. The oxide growth kinetics and the corresponding Al flux were calculated based on the oxidation model. The MCrAlY phase equilibrium calculations were conducted in Thermo-Calc and the oxidation-diffusion simulations were carried out using the finite difference diffusion software, DICTRA. It was found that the MCrAlYs exhibit a predominantly dual-phase $\gamma+\beta$ structure at $1000{ }^{\circ} \mathrm{C}$ and above. It was revealed that varying the temperature had a strong effect on the $\beta$-phase depletion in low Alcontent MCrAlYs from DICTRA simulations and available experimental measurements. In
\end{abstract}


addition, it was demonstrated from the diffusion simulations that MCrAlYs with high $\mathrm{Al}$ content exhibit an enhanced lifetime in maintaining the two-phase structure with less $\beta$-phase depletion at high temperatures due to the high $\mathrm{Al}$ and $\beta$-phase content.

Keywords: MCrAlY; Phase equilibrium; $\beta$-phase depletion; DICTRA; Al content

*Corresponding Authors.

E-mails: Hao.Chen@nottingham.edu.cn, guo.hongbo@buaa.edu.cn 


\section{Introduction}

To meet the demands for high gas turbine efficiency, turbine inlet temperatures have reached or even exceeded the maximum service temperature of superalloys [1-3]. It is extremely difficult for superalloy components to maintain their mechanical and chemical stability in such harsh operating environments [4]. Surface protection is thus widely used to protect high temperature components against oxidation and corrosion [5-7]. Among the available high temperature coatings, MCrAlYs appear to be of particular interests due to their capability in forming a stable and protective alumina scale at the coating surface and their customised composition design to meet specific requirements [8-11]. MCrAlYs (where $\mathrm{M}=\mathrm{Co}$ and/or $\mathrm{Ni}$ ) are multi-component alloys and usually consist of fec $\gamma$-Ni and, more importantly, the bec $\beta$ NiAl phase [12]. This $\beta$-NiAl phase is crucial in the chemical behaviour of MCrAlY coatings during oxidation. The formation and growth of alumina requires the continuous consumption of $\mathrm{Al}$, resulting in the Al-rich $\beta$-NiAl phase becoming depleted during exposure to high temperatures [13-15]. Although the internal loss of $\beta$ phase also occurs due to interdiffusion, it has been demonstrated that the interdiffusion can be minimised by applying effective diffusion barriers between the coating and substrate [16-18]. Hence, the $\beta$-phase depletion at the coating surface is a major concern for the durability of MCrAlY coatings. The MCrAlYs eventually lose their protective effects when the $\beta$ phase is completely depleted since the lifetime is determined by the residual amount of the $\beta$-NiAl phase.

The kinetics of Al loss and $\beta$-phase depletion at the coating surface are mainly governed by the oxidation characteristics, which are influenced by a few factors, such as alloy composition $[19,20]$, heat treatment [21-23] and, more apparently, the oxidation temperature $[24,25]$. It has been reported that the phases present in the coating can have a significant influence on the oxidation characteristics and are likely to cause discrepancies in oxide growth and spallation mechanisms $[26,27]$. The types of oxides formed during oxidation are largely affected by the heat treatment history and it is possible to achieve a dense alumina scale when a proper heat 
treatment is given [28]. In addition, the oxide growth rate and the formation of $\alpha-\mathrm{Al}_{2} \mathrm{O}_{3}$ also rely on the oxidation temperature. It is noted that the oxidation of MCrAlY coatings is rather slow when the temperature is below $1000{ }^{\circ} \mathrm{C}$ and the transition of oxides to $\alpha-\mathrm{Al}_{2} \mathrm{O}_{3}$ would not occur $[29,30]$. Since MCrAlY coatings are always utilised in with high temperature conditions (at $1000{ }^{\circ} \mathrm{C}$ or higher), the oxidation process is largely accelerated at such high temperatures, resulting in serious Al loss and $\beta$-phase depletion. Previous work mainly focuses on the oxidation kinetics, oxide growth mechanisms and interdiffusion of various MCrAlY compositions under different exposure conditions [31-33]. Specific temperature concerns related to the $\beta$-phase depletion kinetics have not been reported yet. Furthermore, previous studies on MCrAlYs are mostly limited to commercially available compositions and particular investigations on the design and application of novel MCrAlY compositions are somewhat sparse. With the development of relevant thermodynamic databases, evaluation of commercially unavailable MCrAlY compositions can be achieved. This is of interest in developing customised MCrAlY compositions to fit particular applications.

Therefore, the aim of this work is to elucidate the kinetics of $\beta$-phase depletion at different temperatures in various MCrAlYs, in an attempt to design novel MCrAlY compositions. Thermo-Calc and DICTRA software are employed to conduct the phase equilibrium calculations and diffusion simulations using the TTNi7 and MOB2 thermodynamic databases $[34,35]$. Since MCrAlY coatings are generally exposed to extremely high temperatures, the oxidation-diffusion simulations of free-standing coatings are thus performed at $1000{ }^{\circ} \mathrm{C}, 1100$ ${ }^{\circ} \mathrm{C}$ and $1200{ }^{\circ} \mathrm{C}$ for times up to $250 \mathrm{~h}$. Furthermore, it appears that MCrAlY coatings with high $\beta$-phase fractions are likely to have an enhanced coating lifetime at high temperatures; to allow the theoretical evaluation of lifetime prediction in various MCrAlY coating alloys, a commercially available MCrAlY composition and two modelled compositions with different $\beta$-phase fractions are used for diffusion simulations. The calculated $\beta$-phase depletion from the three MCrAlY compositions are compared to elucidate the temperature effects on the 
lifetime of MCrAlYs after high temperature exposure. Microstructural analysis and isothermal oxidation are carried out for the commercially available MCrAlY composition to validate the DICTRA calculated results. The two modelled MCrAlY compositions with different $\beta$-phase fractions are not yet commercially available and the corresponding comparisons to the experimental data are not possible. But it is part of the aims in this study to predict the $\beta$ phase depletion behaviour in the commercially unavailable MCrAlYs, as an attempt towards designing new MCrAlY compositions.

\section{Modelling procedure}

\subsection{Thermodynamic modelling}

Phase transformations occur when one or more phases in the system change into a new phase or mixture of phases, due to the fact that the initial state of the system is unstable when the temperature changes. The diffusion of atoms from one state to another is driven by the system to decrease the Gibbs free energy. Subsequently, by knowing the thermodynamic properties of various phases from the available thermodynamic databases, phase equilibria calculations are achieved by Thermo-Calc through Gibbs free energy minimisation routines. The phase compositions and distributions as a function of temperature can then be obtained. Since the microstructures of MCrAlYs vary with $\mathrm{Al}$ concentration, especially in terms of the $\beta$-phase fraction, one commercially available composition and two self-designed MCrAlY compositions with different $\mathrm{Al}$ concentrations are studied. The compositions are tabulated in Table 1, in which the MCrAlY-8 referred to is the commercially available Praxair CO-210-24 composition. Co is used as the base element and the small amount of $\mathrm{Y}$ is neglected here due to its unavailability in the database. The liquid, fcc $\gamma, \gamma^{\prime}, \beta$-NiAl and $\sigma$ phases are considered and other phases that are not related to MCrAlY are suspended in Thermo-Calc.

\subsection{DICTRA diffusion simulations}


Since Thermo-Calc can only provide the equilibrium information, the evolution of element distribution in the system due to the diffusion process cannot be realised; however, this process can be simulated by the diffusion software, DICTRA, which combines the thermodynamic data from Thermo-Calc and its own kinetic mobility data. It allows the elemental diffusion in the system to be modelled through one-dimensional finite difference simulation methods. The nodal phase equilibrium during the diffusion simulation is calculated and the element distribution and phase fraction as a function of system distance are obtained at specified diffusion temperatures. Unlike the conventional diffusion theories that assume diffusion occurs due to the concentration gradient, DICTRA uses an alternative approach, considering that diffusion is driven by the local chemical potential gradient of elements. Equilibrium of the system is reached when the chemical potential of each individual element becomes homogeneous across the whole system. Further details on how DICTRA works can be found elsewhere [34].

\subsubsection{Oxide growth kinetics}

Since $\beta$-phase depletion is driven by oxidation at the coating surface, the oxide growth kinetics is crucial to the $\beta$-phase depletion. Generally, MCrAlY coatings are subjected to an initial heat treatment at $1100{ }^{\circ} \mathrm{C}$ for $2 \mathrm{~h}$ prior to oxidation exposure. This heat treatment has been demonstrated to be effective in facilitating the $\mathrm{Al}_{2} \mathrm{O}_{3}$ growth at the surface [36]. Thus, it is assumed here that only $\mathrm{Al}_{2} \mathrm{O}_{3}$ grows at the surface. Among various oxidation models reported in the literature, the temperature dependent oxide growth kinetics proposed by Meier et al. is employed below to approximate the oxide growth at $1000{ }^{\circ} \mathrm{C}, 1100{ }^{\circ} \mathrm{C}$ and $1200{ }^{\circ} \mathrm{C}$ [37],

$$
\delta_{(\mu m)}=\left\{\exp \left[Q\left(\frac{1}{T_{0}}-\frac{1}{T}\right)\right] t\right\}^{n}
$$


where $\mathrm{Q}, \mathrm{T}_{0}$ and $\mathrm{n}$ were extrapolated from the experimental data between $1000 \sim 1200{ }^{\circ} \mathrm{C}$ and were reported as $27,777.4 \mathrm{~K}, 2423.7 \mathrm{~K}$ and 0.332 respectively. By taking the differential of Eq. (1) with respect to time, the oxide growth rate against oxidation time is then obtained in Eq. (2). The above parameters for the oxide growth model and the time-dependent oxide growth rate model are summarised in Table 2.

$$
\dot{\delta}_{(\mu m / s)}=n\left\{\exp \left[Q\left(\frac{1}{T_{0}}-\frac{1}{T}\right)\right]\right\}^{n} t^{n-1}
$$

\subsubsection{Initial conditions}

It is reported that a thin alumina scale tends to grow during the initial heat treatment [36]. To address this effect on the initial state of the coating alloy prior to oxidation, an initial layer of $\mathrm{Al}_{2} \mathrm{O}_{3}$ is assumed. By knowing the initial oxide thickness, an initial $\beta$-phase depletion zone can be calculated by assuming the $\beta$-NiAl phases are depleted to form the $\mathrm{Al}_{2} \mathrm{O}_{3}$. The $\beta$-phase depletion zone, which only exhibits a single $\gamma$-phase structure, is represented by the composition of the $\gamma$ phase. The overall MCrAlY composition is used in the two-phase $\gamma+\beta$ region. This one-dimensional model is defined as $250 \mu \mathrm{m}$ which is the typical coating thickness in industrial applications. Grids of $0.2 \mu \mathrm{m}$ and $2 \mu \mathrm{m}$, as illustrated in Fig. 1, are employed here for diffusion simulations. The fine grid spacing close to the surface allows reliable investigations in the first $50 \mu \mathrm{m}$ where the $\beta$-phase depletion occurs. The elements involved in the diffusion calculations are $\mathrm{Al}, \mathrm{Ni}, \mathrm{Co}, \mathrm{Cr}$. The $\gamma$-fcc is defined as the matrix phase and the $\beta$-NiAl and $\sigma$ phases are defined as dispersed phases with equilibrium compositions. Since the dispersed phases are treated as non-diffusional phases and diffusion only occurs in the $\gamma$-fcc phase in DICTRA, a labyrinth factor is thus introduced here to approximate the effective diffusivity [38, 39], as given in Eq. (3), 


$$
D_{e f f}=D_{\gamma} \cdot\left(1+\frac{3-3 f_{\gamma}^{V}}{f_{\gamma}^{V}-\frac{10}{3}}\right)
$$

where $\mathrm{D}_{\text {eff }}$ is the effective diffusivity, $\mathrm{D}_{\gamma}$ is the diffusivity for $\gamma$ and $f_{\gamma}^{V}$ is the volume fraction of the $\gamma$ phase. The term in the bracket is the labyrinth factor and is used as an approximation for the effective diffusivity of the MCrAlYs in DICTRA simulations.

\subsubsection{Boundary conditions}

The growth of $\mathrm{Al}_{2} \mathrm{O}_{3}$ at the surface requires an $\mathrm{Al}$ flux from the MCrAlY to be determined. This Al flux can be derived from the oxide growth kinetics in Eq. (2), and through a mass balance conversion, the $\mathrm{Al}$ flux can be obtained in Eq. (4),

$$
J_{A l}=\dot{\delta} \cdot \rho_{o x} \cdot r
$$

where $\dot{\delta}$ is represented from Eq. (2), $\rho_{o x}$ is the oxide density (assuming $3950 \mathrm{~kg} / \mathrm{m}^{3}$ for $\mathrm{Al}_{2} \mathrm{O}_{3}$ ), and $\mathrm{r}$ is the converting ratio. It is further noticed from Eq. (2) that $\dot{\delta}$ is infinite when $\mathrm{t}$ $=0$ (at the beginning of oxidation). This leads to an infinite Al flux at the boundary since Eq. (4) relies on Eq. (2). It is assumed here that the initial $\mathrm{Al}_{2} \mathrm{O}_{3}$ is $1 \mu \mathrm{m}$ in thickness. The $\mathrm{Al}$ flux functions at different temperatures are plotted in Fig. 2 and the starting Al flux for each temperature condition is also highlighted. The simulation time is $250 \mathrm{~h}$ at $1000 \mathrm{~s}$ per step via a fully implicit solution method.

\section{Modelling results}

\subsection{Phase equilibria calculations}

The phase fraction plots of the three MCrAlY compositions listed in Table 1 are shown in Fig. 3. It can be seen that the MCrAlYs exhibit a primary two-phase $\gamma+\beta$ structure at high temperatures and the $\gamma^{\prime}$ and $\sigma$ are formed at low temperatures. The changes of the phase fractions against temperature depend on the equilibrium state of the system to minimise the 
Gibbs free energy. The $\beta$-phase fraction decreases with temperature but increases with $\mathrm{Al}$ content. It is also found that the $\sigma$ phase appears to be one of the equilibrium phases in the MCrAlY-12 at $1000{ }^{\circ} \mathrm{C}$ in Fig. 3c, but at a rather small fraction. The composition of the minor $\sigma$ phase is tabulated in Table 3, with high $\mathrm{Cr}$ and Co concentration and small Al concentration, which agrees well with previous experimental and modelled results [40]. Since the fraction of the $\sigma$ phase is small and very limited Al exists in the $\sigma$ phase, it is thus believed that the minor $\sigma-(\mathrm{Cr}, \mathrm{Co})$ phase would not affect the subsequent $\beta$-phase depletion.

Fig. 4 depicts the relationship between the phase fractions and Al content at different temperatures. It is evident that the $\beta$-phase fraction increases with $\mathrm{Al}$, indicating that $\mathrm{Al}$ has a stabilising effect on the $\beta$ phase formation. It is also noticed that the $\beta$-phase fraction decreases with temperature from the thermodynamic calculations, which is based on the equilibrium state of the alloy system at increasing temperatures. From the data presented in Fig. $4 \mathrm{~b}$, it can be found that the mass fraction of the $\beta$ phase is likely to decrease by $5 \%$ when the temperature increases by $100{ }^{\circ} \mathrm{C}$ at a given $\mathrm{Al}$ content and the mass fraction of the $\beta$ phase roughly increases by $7.5 \%$ when the $\mathrm{Al}$ content increases by $1 \mathrm{wt} \%$ at a given temperature. Fig. 5 shows the phase compositions of MCrAlY-8, MCrAlY-10 and MCrAlY-12 at different temperatures. $\mathrm{Cr}$ concentration in the $\gamma$ phase increases with $\mathrm{Al}$ whilst $\mathrm{Ni}$ decreases as $\mathrm{Al}$ content increases. No remarkable changes in Al and Co concentration in the $\gamma$ phase are found from Fig. 5a. It is further shown from Fig. 5b that the $\beta$-phase compositions are almost identical for different Al contents and temperatures. This means that the addition of Al mainly results in the increase of the $\beta$-phase fraction while the composition of the $\beta$ phase is largely unchanged, showing good consistency with the reported work by Achar et al. on the phase equilibria of MCrAlYs [41].

\section{2. $\beta$-phase depletion kinetics}


Fig. 6 depicts the oxide growth kinetics according to Eq. (1). An increase in the oxide growth is seen when the temperature increases. The oxide growth rate is plotted as a function of time in Fig. 7 according to Eq. (2). It is shown that the oxide growth rate is larger at $1200{ }^{\circ} \mathrm{C}$ compared to that at $1000{ }^{\circ} \mathrm{C}$ and $1100{ }^{\circ} \mathrm{C}$ within the same time intervals, indicating that temperature has a strong influence on the oxide growth kinetics and the subsequent $\beta$-phase depletion kinetics. The evolution of the phase fraction against oxidation time for MCrAlY-8, MCrAlY-10 and MCrAlY-12 at different temperatures is given in Fig. 8, Fig. 9 and Fig. 10 respectively. It can be seen that the $\beta$ phase depletes continuously with time in the three MCrAlYs, more significantly so at $120{ }^{\circ} \mathrm{C}$. For the MCrAlY-8, it can be observed in Fig. 8c that the $\beta$ phase has become significantly depleted after 250 -h of oxidation at $1200^{\circ} \mathrm{C}$ due to the large Al flux at this temperature. For MCrAlY-10 and MCrAlY-12 in Fig. 9 and Fig. 10, since a higher $\beta$-phase fraction exists initially, the $\beta$-phase fraction in the two-phase region largely maintains the original value when the temperature is increased. The MCrAlY-12, which has the highest $\beta$-phase fraction, exhibits the lowest $\beta$-phase depletion at all temperatures, showing an enhanced lifetime during oxidation. It is noted that the minor $\sigma$ phase only forms in the MCrAlY-12 at $1000^{\circ} \mathrm{C}$. Since the fraction of $\sigma$ phase is small and the Al concentration in the $\sigma$ phase is very limited, the depletion of the $\sigma$ phase is not of much concern.

The element profiles after $100 \mathrm{~h}$ oxidation simulation for the three MCrAlYs are summarised in Fig. 11. The loss of $\mathrm{Al}$ due to the oxidation kinetics causes the chemical potential of $\mathrm{Co}, \mathrm{Ni}$ and $\mathrm{Cr}$ to redistribute. To achieve a new equilibrium state of the system, the concentrations of other elements are calculated to balance the local chemical potential difference. The element distribution against distance is similar at different temperatures for each alloy, except for the $\beta$-phase depletion zone, which varies with temperature. It is also found that a large Al depletion zone has developed in the MCrAlY-8 at $120{ }^{\circ} \mathrm{C}$, which correlates well with Fig. 8c. For the other two MCrAlYs, since they have high Al content, no significant Al depletion 
occurred. Fig. 12 summarises the calculated $\beta$-phase depletion. For MCrAlY-8 in Fig. 12a, the $\beta$-phase depletion is relatively slow at $1000{ }^{\circ} \mathrm{C}$ but becomes much larger at $1200{ }^{\circ} \mathrm{C}$, showing the strong effect of temperature on the $\beta$-phase depletion. For MCrAlY-10 and MCrAlY-12 in Fig. 12b and Fig. 12c, smaller $\beta$-phase depletion zones are developed compared to MCrAlY-8 at the same temperatures. The MCrAlY-12 shows a much lower level of $\beta$-phase depletion, which can be attributed to the fact that the MCrAlY-12 has the highest Al content and $\beta$-phase fraction. It is also noticed that the $\beta$-phase depletion in MCrAlY-12 at $1200{ }^{\circ} \mathrm{C}$ is much smaller than the other two alloys, indicating that the temperature effects on the kinetics of the $\beta$-phase depletion in high Al-content MCrAlYs are not that significant compared to the MCrAlY-8 with a low $\beta$-phase fraction.

\section{Experimental validation}

A commercially available Praxair CoNiCrAlY powder (known as CO-210-24) is used to prepare free-standing coating alloy by HVOF spraying. This powder composition is the same as the MCrAlY-8 in Table 1 and can be used to identify the microstructure and phase distribution calculated in Fig. 3. The microstructure of the MCrAlY-8 after annealing at different temperatures is shown in Fig. 13. A two-phase structure is clearly seen. Some micron-sized oxide particles/stringers with a volume fraction of less than $1 \%$ are also found to exist in Fig. 13. The volume fraction of the $\beta$ phase can be measured by image analysis. Due to the unavailability of the volume data in the TTNi7 database, in order to compare with the calculated mass fractions from Fig. 3a, the volume fraction of the $\beta$ phase is converted to mass fraction by Eq. (5),

$$
f_{\beta}^{M}=\frac{\rho_{\beta} f_{\beta}^{V}}{\rho_{\gamma} f_{\gamma}^{V}+\rho_{\beta} f_{\beta}^{V}}
$$

where $f_{\gamma}^{V}$ and $f_{\beta}^{V}$ are the volume fraction of the $\gamma$ and $\beta$ phase measured from Fig. 13, and $\rho_{\gamma}$ and $\rho_{\beta}$ are the density of the $\gamma$ and $\beta$ phase, taken as $7.83 \times 10^{3} \mathrm{~kg} / \mathrm{m}^{3}$ and $6.81 \times 10^{3} \mathrm{~kg} / \mathrm{m}^{3}$ 
respectively [42]. The converted mass fraction from the measured volume fraction is thus plotted in Fig. 14 to compare with the modelled $\beta$-phase mass fraction. It is shown that the thermodynamic data from TTNi7 database correlates well with the experimental measurements of the MCrAlY-8. However, the MCrAlY-10 and MCrAlY-12 are not yet commercially available, thus experimental observations are not possible. But since good consistency between the experimental and predicted phase fractions has been demonstrated for the MCrAlY-8 in Fig. 14 and considering that only small variations in the Al content are introduced, it is believed that the calculated microstructural information for MCrAlY-10 and MCrAlY-12 in Fig. 3b and Fig. 3c is reasonable.

Prior to oxidation exposure, the as-received MCrAlY-8 samples from thermal spraying are heat treated at $1100{ }^{\circ} \mathrm{C}$ for $2 \mathrm{~h}$ to aid the growth of alumina during oxidation. This aligns with the initial conditions in the DICTRA model. The microstructure of the MCrAlY-8 after isothermal oxidation for $100 \mathrm{~h}$ at different temperatures is shown in Fig. 15. The oxide layer is mainly composed of alumina and very few spinel oxides are found to exist, which is supported by the XRD pattern in Fig. 15 d. The MCrAlY- 8 still exhibits the two-phase $\gamma+\beta$ structure after high temperature exposure. The experimentally measured $\beta$-phase depletion is compared with the modelling results in Fig. 12a. Reasonable agreement is shown in Fig. 12a between experiments and predictions. Since nearly parabolic oxide growth behaviour is used in the diffusion model, similar parabolic kinetics is expected for the $\beta$-phase depletion. Due to the unavailability of the MCrAlY-10 and MCrAlY-12 powder, direct experimental inspection is not possible. But Fig. $3 \mathrm{~b}$ and Fig. $3 \mathrm{c}$ have shown that the primary phases in these two alloys are $\gamma+\beta$ at high temperatures. It is also illustrated from Fig. 5 that the composition of the $\beta$ phase remains largely unchanged. Hence, the mechanism of Al loss, which is driven by the oxide growth, is believed to be similar in MCrAlY-10 and MCrAlY-12. These two alloys have higher $\beta$-phase fraction, acting as more effective $\mathrm{Al}$ reservoir, and less loss of $\beta$ phase is thus expected. This is supported by Fig. 12b and Fig. 12c when compared with MCrAlY-8 in 
Fig. 12a. Therefore, considering that there is no significant change in the phase structure and mechanism of Al loss in MCrAlY-10 and MCrAlY-12, the simulated evolution of the $\beta$-phase in Fig. 12b and Fig. 12c is reasonable.

\section{Discussion}

\subsection{Effects of Al content}

The thermodynamic calculations in Fig. 4 and Fig. 5 show that the additions of Al can increase the $\beta$-phase fraction in MCrAlYs without large changes in the $\beta$-phase composition. Since the $\beta$ phase is defined as the dispersed non-diffusional phase in the thermodynamic database, its composition is unlikely to undergo significant changes. This also agrees well with its unique B2-type bcc structure [43]. As a result, the range of the $\beta$-phase composition is restricted in order to maintain the $\mathrm{B} 2 \mathrm{bcc}$ structure. The minor $\sigma-(\mathrm{Cr}, \mathrm{Co})$ phase that tends to form in high Al-content MCrAlYs has limited influence on the $\beta$ phase because the $\mathrm{Al}$ concentration in the $\sigma$ phase is rather small. It has been reported that the alloy composition is a major factor influencing the oxidation kinetics [44-46]. The oxidation model reported by Meier et al. in Eq. (1) is based on a composition of Ni22Co17Cr12.5A10.5Y0.4Si0.25Hf, which is different from the MCrAlY compositions in this work; however, Eq. (1) has been successfully applied to an oxidation-diffusion model of a Ni23Co15Cr8.5Al7Ta coating by Karunaratne et al. [47]. It can be seen that the major difference between the above two compositions is the Al content. This means that the oxidation model in Eq. (1) has shown the capability of modelling MCrAlYs at different Al-contents. Furthermore, the effects of different oxide growth models on the subsequent $\beta$-phase depletion have been investigated in one of our previous studies [48]. No significant difference in the calculated $\beta$-phase depletion was reported when using Eq. (1) or self-derived oxide growth models and the predicted $\beta$ phase depletion from different oxidation models showed reasonable agreements with the experimental measurements for Co32Ni21Cr8A10.5Y. Brandl et al. also report that the 
oxidation rates for their MCrAlY coatings with $8 \mathrm{wt} \% \mathrm{Al}$ and $12 \mathrm{wt} \% \mathrm{Al}$ are the same apart from the oxide morphology [45]. Thus, given that there is no generic oxidation model available, the oxidation model in Eq. (1) was adopted in this work as a more generic representation of the oxide growth kinetics. Considering only small variations in the $\mathrm{Al}$ contents are introduced, it is believed that Meier's model is suitable for Co32Ni21Cr8A10.5Y and is capable of predicting the $\beta$-phase depletion of this MCrAlY at different Al-contents. It has been further reported that different spraying processes may also have large impact on the oxidation kinetics $[49,50]$. While the MCrAlY in the work of Meier et al. has been applied by low-pressure chamber spraying, the MCrAlY in this work was applied by means of the HVOF process. This is likely to cause some discrepancies in the subsequent diffusion calculations. But since Eq. (1) has been previously demonstrated to be suitable for the MCrAlYs used in this work and reasonable agreements have been achieved between model predictions and experimental measurements for the HVOF sprayed MCrAlYs in previous studies [39, 48], the oxidation model in Eq. (1) is thus assumed here to approximate the oxide growth. This may still result in discrepancies between the modelling and experimental results. Given that the focus of this work is to present a systematic numerical modelling of MCrAlYs with different Al-contents and their response on the $\beta$-phase depletion, the assumption and approximation are believed to be reasonable, as a first attempt towards designing new bondcoat compositions. It is therefore acceptable to assume that the oxidation kinetics and the Al flux are temperature dependent in this study. The Al loss will be the same in the MCrAlYs at a given temperature. As a result, smaller $\beta$-phase depletion zones are expected in the MCrAlYs with high $\beta$-phase fractions, i.e. MCrAlY-12.

In the current two phase $\gamma+\beta$ MCrAlY systems, the addition of Al to the overall composition does not lead to significant microstructure changes. However, cautions must be taken as the addition of $\mathrm{Al}$ can result in higher amounts of $\beta$ phase and cause the $\sigma$ phase to precipitate. It has been reported that the bcc $\beta$ phase exhibits a ductile-to-brittle transition behaviour [51]. 
The addition of extra Al can increase the ductile-to-brittle transition temperature, leaving a broad temperature regime for the brittle behaviour of MCrAlYs [52]. This can be detrimental to the mechanical performance of the alloys because fast fracture may occur due to the increased brittleness at high $\mathrm{Al}$ content. Another aspect to consider is the formation of the minor $\sigma-(\mathrm{Cr}, \mathrm{Co})$ phase due to the increase of $\mathrm{Al}$ content. According to current work, the $\sigma$ phase only forms in $\mathrm{MCrAlY}-12$ at $1000{ }^{\circ} \mathrm{C}$. It is reported that the $\sigma$ phase is highly undesirable in MCrAlYs due to its poor mechanical performance [41]. Fig. 3 shows that the $\sigma$ phase tends to precipitate at high $\mathrm{Al}$ content. Thus, further considerations need to be taken to avoid the formation of $\sigma$ phase when $\mathrm{Al}$ content increases.

\subsection{Effects of temperature}

The microstructure of MCrAlY-8 in Fig. 13 shows the nearly globular morphology and irregular shapes of the $\beta$ phase, indicating a large surface energy. A previous $\beta$-phase coarsening study has revealed that the $\gamma / \beta$ interface in MCrAlY- 8 exhibits large interfacial energies $\left(>200 \mathrm{~mJ} / \mathrm{m}^{2}\right)$ at temperatures above $1000{ }^{\circ} \mathrm{C}[42]$. Rapid dissolution of the $\beta$ phase may occur when the temperature increases in order to minimise the interfacial energy of the system. Thus, for the MCrAlYs in Table 1, a reduction in the $\beta$-phase fraction is expected when the temperature increases. This agrees well with the thermodynamic calculations in Fig. 4 when comparing the $\beta$-phase fraction at different temperatures. Meanwhile, it is known from Fig. 6 and Fig. 7 that the oxidation kinetics and Al flux increase with temperature. The MCrAlY-8, which has low $\mathrm{Al}$ content and a small $\beta$-phase fraction, cannot meet the accelerated loss of $\mathrm{Al}$ at $1200{ }^{\circ} \mathrm{C}$, resulting in substantial loss of $\beta$ phase in the alloy. This is indeed seen from Fig. $8 \mathrm{c}$ after $250 \mathrm{~h}$ at $1200{ }^{\circ} \mathrm{C}$. It is further indicated that the MCrAlY-8 starts to lose its protective effects due to the increase of Al flux and the loss of $\beta$ phase at $1200{ }^{\circ} \mathrm{C}$. In terms of the $\beta$-phase depletion, the MCrAlY-10 and MCrAlY-12 show an 
enhanced lifetime, as seen from Fig. 9 and Fig. 10 when comparing the size of the remaining two-phase regions.

Another important factor to be considered is the change of diffusion coefficient due to the temperature increase. The general Arrhenius representation of the diffusion coefficient is given in Eq. (6),

$$
D=D_{0} \exp \left(-\frac{Q}{R T}\right)
$$

where $\mathrm{D}, \mathrm{D}_{0}, \mathrm{Q}, \mathrm{R}$ and $\mathrm{T}$ are the diffusion coefficient, frequency factor, activation energy, global gas constant and oxidation temperature respectively. It indicates that the increase of oxidation temperature would increase the element diffusion coefficient. Although DICTRA uses the diffusion coefficient matrix to perform the element diffusion, the above equation can still be used as a quick approximation for the temperature dependent diffusion coefficient. The increase of the diffusion coefficient means that the element diffusion, especially the $\mathrm{Al}$ depletion, becomes faster as the temperature increases. It has also been reported that the grain size of the thermally sprayed MCrAlYs is in sub-micron range [53,54]. The grain boundaries in such fine-grained structure can act as fast diffusion paths for elements like Al with small atomic radius in MCrAlY systems [55]. Since only Al loss is considered, the diffusion of Al can be approximated by Eq. (7),

$$
x_{d} \sim \sqrt{D_{e f f} t}
$$

where $x_{d}$ is the Al diffusion distance or, more simply, the $\beta$-phase depletion zone. It can be seen from Eq. (6) and Eq. (7) that the $\beta$-phase depletion kinetics are proportional to the oxidation temperature. To further demonstrate the effects of temperature and $\mathrm{Al}$ content on the $\beta$-phase depletion kinetics, Table 4 summarises the effective diffusion coefficients in the MCrAlYs at different temperatures according to Eq. (7). The effect of temperature on the $\beta$ phase depletion kinetics in MCrAlY-8 is very significant, in which the $\mathrm{D}_{\text {eff }}$ in MCrAlY-8 increases by one order of magnitude when the temperature increases by $100{ }^{\circ} \mathrm{C}$. Meanwhile, 
the increase of $\mathrm{D}_{\text {eff }}$ in MCrAlY-10 and MCrAlY-12 is not as large as that in MCrAlY-8 when the temperature increases. As can be seen from Table 4, among the three MCrAlYs studied in the present work, MCrAlY-12 exhibits the smallest $\beta$-phase depletion kinetics at all temperatures, showing an enhanced lifetime under oxidation compared to the other two MCrAlYs.

\section{Conclusions}

The phase equilibria in the three MCrAlYs were modelled and the $\beta$-phase depletion was investigated at $1000^{\circ} \mathrm{C}, 1100{ }^{\circ} \mathrm{C}$ and $1200^{\circ} \mathrm{C}$. The main conclusions were as follows:

- The phase equilibria calculations revealed that the MCrAlYs used in this study mainly exhibit a $\gamma+\beta$ phase structure. It was found that the addition of Al to the overall MCrAlY composition has a strong influence on the amount of the $\beta$ phase. This is likely due to the $\mathrm{Al}$ in the MCrAlYs acting as the stabilising element on the $\beta$ phase.

- The $\beta$-phase depletion behaviour was modelled using the temperature-dependent oxide growth kinetics as the boundary condition at $1000{ }^{\circ} \mathrm{C}, 1100{ }^{\circ} \mathrm{C}$ and $1200{ }^{\circ} \mathrm{C}$. MCrAlY-8 exhibited the largest $\beta$-phase depletion zone and MCrAlY-12, with the highest $\beta$-phase fraction, showed an improved lifetime under oxidation. It was revealed that the addition of $\mathrm{Al}$ to $\mathrm{MCrAlYs}$ could increase the $\beta$-phase fraction and achieve an enhanced lifetime performance during oxidation.

- Significant $\beta$-phase loss occurred in the MCrAlY-8 at $1200{ }^{\circ} \mathrm{C}$ due to its limited amount of $\beta$ phase. The other two MCrAlYs with higher $\beta$-phase fractions could maintain sufficient $\beta$ phase after oxidation at $1200{ }^{\circ} \mathrm{C}$.

- Experimental observations on MCrAlY-8 showed good agreements with the modelling results. The simulated $\beta$-phase depletion results for MCrAlY-10 and MCrAlY-12 are believed to be reasonable since no significant changes in the phase 
structure and Al-loss mechanism occurred, even though the MCrAlY-10 and MCrAlY-12 are not commercially available yet.

\section{Acknowledgements}

The authors would like to thank Prof. John Nicholls, Prof. Graham McCartney and Dr. Katy Voisey for helpful discussions. The authors would like to acknowledge Prof. Graham McCartney for providing the access to Thermo-Calc and DICTRA computing facilities at the Faculty of Engineering, University of Nottingham. This research was supported by Zhejiang Provincial Natural Science Foundation of China under Grant No. LQ18E010002, Ningbo Natural Science Foundation under Grant No. 2018A610168 and Qianjiang Talent Scheme under Grant No. QJD1803012.

\section{References}

[1] C.U. Hardwicke, Y.-C. Lau, Advances in Thermal Spray Coatings for Gas Turbines and Energy Generation: A Review, J. Therm. Spray Technol. 22 (2013) 564-576.

[2] H. Chen, G.A. Jackson, W. Sun, An Overview of Using Small Punch Testing for Mechanical Characterization of MCrAlY Bond Coats, J. Therm. Spray Technol. 26 (2017) 1222-1238.

[3] X. Gong, H. Peng, Y. Ma, H. Guo, S. Gong, Microstructure evolution of an EB-PVD NiAl coating and its underlying single crystal superalloy substrate, J. Alloys Compd. 672 (2016) $36-44$.

[4] J.R. Nicholls, Designing oxidation-resistant coatings, JOM 52 (2000) 28-35.

[5] A.G. Evans, D.R. Mumm, J.W. Hutchinson, G.H. Meier, F.S. Pettit, Mechanisms controlling the durability of thermal barrier coatings, Prog. Mater. Sci. 46 (2001) 505-553. [6] J.R. Nicholls, N.J. Simms, W.Y. Chan, H.E. Evans, Smart overlay coatings - concept and practice, Surf. Coat. Technol. 149 (2002) 236-244.

[7] R. Darolia, Thermal barrier coatings technology: critical review, progress update, remaining challenges and prospects, Int. Mater. Rev. 58 (2013) 315-348.

[8] H. Chen, D.G. McCartney, K.T. Voisey, Effect of surface conditions on internal oxidation and nitridation of HVOF MCrAlY coatings, Mater. High Temp. 32 (2015) 215-220.

[9] P. Richer, M. Yandouzi, L. Beauvais, B. Jodoin, Oxidation behaviour of CoNiCrAlY bond coats produced by plasma, HVOF and cold gas dynamic spraying, Surf. Coat. Technol. 204 (2010) 3962-3974.

[10] B. Rajasekaran, G. Mauer, R. Vaßen, Enhanced Characteristics of HVOF-sprayed MCrAlY Bond Coats for TBC Applications, J. Therm. Spray Technol. 20 (2011) 1209-1216. [11] H. Chen, A. Rushworth, W. Sun, J. He, H. Guo, Some considerations in using the small punch testing for thermally sprayed CoNiCrAlY coatings, Surf. Coat. Technol. 357 (2019) 684-690. 
[12] D. Texier, D. Monceau, F. Crabos, E. Andrieu, Tensile properties of a non-line-of-sight processed $\beta-\gamma-\gamma^{\prime}$ MCrAlY coating at high temperature, Surf. Coat. Technol. 326 (2017) 2836.

[13] T. Mori, S. Kuroda, H. Murakami, H. Katanoda, Y. Sakamoto, S. Newman, Effects of initial oxidation on $\beta$ phase depletion and oxidation of CoNiCrAlY bond coatings fabricated by warm spray and HVOF processes, Surf. Coat. Technol. 221 (2013) 59-69.

[14] J. Toscano, D. Naumenko, A. Gil, L. Singheiser, W.J. Quadakkers, Parameters affecting TGO growth rate and the lifetime of TBC systems with MCrAlY-bondcoats, Mater. Corros. 59 (2008) 501-507.

[15] H. Chen, Application of Precipitate Free Zone Growth Kinetics to the $\beta$-Phase Depletion Behavior in a CoNiCrAlY Coating Alloy: An Analytical Approach, Metall. Mater. Trans. A 49 (2018) 2551-2560.

[16] Z. Bai, D. Li, H. Peng, J. Wang, H. Guo, S. Gong, Suppressing the formation of SRZ in a Ni-based single crystal superalloy by RuNiAl diffusion barrier, Progress in Natural Science: Materials International 22 (2012) 146-152.

[17] E. Cavaletti, S. Naveos, S. Mercier, P. Josso, M.P. Bacos, D. Monceau, Ni-W diffusion barrier: Its influence on the oxidation behaviour of a $\beta-(\mathrm{Ni}, \mathrm{Pt}) \mathrm{Al}$ coated fourth generation nickel-base superalloy, Surf. Coat. Technol. 204 (2009) 761-765.

[18] C. Guo, W. Wang, Y. Cheng, S. Zhu, F. Wang, Yttria partially stabilised zirconia as diffusion barrier between NiCrAlY and Ni-base single crystal René N5 superalloy, Corros. Sci. 94 (2015) 122-128.

[19] Y. Li, C.-J. Li, Q. Zhang, L.-K. Xing, G.-J. Yang, Effect of Chemical Compositions and Surface Morphologies of MCrAlY Coating on Its Isothermal Oxidation Behavior, J. Therm. Spray Technol. 20 (2010) 121-131.

[20] D. Seo, K. Ogawa, Y. Suzuki, K. Ichimura, T. Shoji, S. Murata, Comparative study on oxidation behavior of selected MCrAlY coatings by elemental concentration profile analysis, Appl. Surf. Sci. 255 (2008) 2581-2590.

[21] D. Salehi Doolabi, M.R. Rahimipour, M. Alizadeh, S. Pouladi, S.M.M. Hadavi, M.R. Vaezi, Effect of high vacuum heat treatment on microstructure and cyclic oxidation resistance of HVOF-CoNiCrAlY coatings, Vacuum 135 (2017) 22-33.

[22] M. Tahari, M. shamanian, M. salehi, The effect of heat treatment and thermal spray processes on the grain growth of nanostructured composite CoNiCrAlY/YSZ powders, J. Alloys Compd. 646 (2015) 372-379.

[23] P. Poza, P.S. Grant, Microstructure evolution of vacuum plasma sprayed CoNiCrAlY coatings after heat treatment and isothermal oxidation, Surf. Coat. Technol. 201 (2006) 28872896.

[24] E. Prieto-García, F.J. Baldenebro-Lopez, I. Estrada-Guel, J.M. Herrera-Ramírez, R. Martínez-Sánchez, Microstructural evolution of mechanically alloyed Ni-based alloys under high temperature oxidation, Powder Technol. 281 (2015) 57-64.

[25] M. Bensch, A. Sato, N. Warnken, E. Affeldt, R.C. Reed, U. Glatzel, Modelling of High Temperature Oxidation of Alumina-Forming Single-Crystal Nickel-Base Superalloys, Acta Mater. 60 (2012) 5468-5480.

[26] T. Nijdam, W. Sloof, Effect of Y Distribution on the Oxidation Kinetics of NiCoCrAlY Bond Coat Alloys, Oxid. Met. 69 (2008) 1-12.

[27] A. Gil, D. Naumenko, R. Vassen, J. Toscano, M. Subanovic, L. Singheiser, W.J.

Quadakkers, Y-rich oxide distribution in plasma sprayed MCrAlY-coatings studied by SEM with a cathodoluminescence detector and Raman spectroscopy, Surf. Coat. Technol. 204 (2009) 531-538.

[28] P. Puetz, X. Huang, R.S. Lima, Q. Yang, L. Zhao, Characterization of transient oxide formation on CoNiCrAlY after heat treatment in vacuum and air, Surf. Coat. Technol. 205 (2010) 647-657. 
[29] L. Lelait, S. Alpérine, R. Mévrel, Alumina scale growth at zirconia-MCrAlY interface: a microstructural study, J. Mater. Sci. 27 (1992) 5-12.

[30] P. Niranatlumpong, C.B. Ponton, H.E. Evans, The Failure of Protective Oxides on Plasma-Sprayed NiCrAlY Overlay Coatings, Oxid. Met. 53 (2000) 241-258.

[31] J. Lv, X. Fan, Q. Li, The impact of the growth of thermally grown oxide layer on the propagation of surface cracks within thermal barrier coatings, Surf. Coat. Technol. 309 (2017) 1033-1044.

[32] M. Elsaß, M. Frommherz, A. Scholz, M. Oechsner, Interdiffusion in MCrAlY coated nickel-base superalloys, Surf. Coat. Technol. 307 (2016) 565-573.

[33] H. Zhou, J. Qu, M. Cherkaoui, Finite element analysis of oxidation induced metal depletion at oxide-metal interface, Comput. Mater. Sci. 48 (2010) 842-847.

[34] A. Borgenstam, L. Höglund, J. Ågren, A. Engström, DICTRA, a tool for simulation of diffusional transformations in alloys, J. Phase Equilib. 21 (2000) 269-280.

[35] J.O. Andersson, T. Helander, L. Höglund, P. Shi, B. Sundman, Thermo-Calc \& DICTRA, computational tools for materials science, Calphad 26 (2002) 273-312.

[36] S. Saeidi, K.T. Voisey, D.G. McCartney, The Effect of Heat Treatment on the Oxidation Behavior of HVOF and VPS CoNiCrAlY Coatings, J. Therm. Spray Technol. 18 (2009) 209216.

[37] S.M. Meier, D.M. Nissley, K.D. Sheffler, Thermal barrier coating life prediction model development, Phase 2 Final Report, Technical Report NASA Contractor Report 18911/NAS323944, (1991).

[38] T. Gómez-Acebo, B. Navarcorena, F. Castro, Interdiffusion in multiphase, Al-Co-Cr-NiTi diffusion couples, J Phs Eqil and Diff 25 (2004) 237-251.

[39] H. Chen, G.A. Jackson, K.T. Voisey, D.G. McCartney, Modelling and experimental study on $\beta$-phase depletion behaviour of HVOF sprayed free-standing CoNiCrAlY coatings during oxidation, Surf. Coat. Technol. 291 (2016) 34-42.

[40] J. Toscano, A. Gil, T. Hüttel, E. Wessel, D. Naumenko, L. Singheiser, W. Quadakkers, Temperature dependence of phase relationships in different types of MCrAlY-coatings, Surf. Coat. Technol. 202 (2007) 603-607.

[41] D.R.G. Achar, R. Munoz-Arroyo, L. Singheiser, W.J. Quadakkers, Modelling of phase equilibria in MCrAlY coating systems, Surf. Coat. Technol. 187 (2004) 272-283.

[42] H. Chen, Y.Q. Si, D.G. McCartney, An analytical approach to the $\beta$-phase coarsening behaviour in a thermally sprayed CoNiCrAlY bond coat alloy, J. Alloys Compd. 704 (2017) 359-365.

[43] R.D. Noebe, R.R. Bowman, M.V. Nathal, Physical and mechanical properties of the B2 compound NiAl, Int. Mater. Rev. 38 (1993) 193-232.

[44] H. Hindam, D.P. Whittle, Microstructure, adhesion and growth kinetics of protective scales on metals and alloys, Oxid. Met. 18 (1982) 245-284.

[45] W. Brandl, H.J. Grabke, D. Toma, J. Krüger, The oxidation behaviour of sprayed MCrAlY coatings, Surf. Coat. Technol. 86-87 (1996) 41-47.

[46] J. Toscano, R. Vaen, A. Gil, M. Subanovic, D. Naumenko, L. Singheiser, W.J. Quadakkers, Parameters affecting TGO growth and adherence on MCrAlY-bond coats for TBC's, Surf. Coat. Technol. 201 (2006) 3906-3910.

[47] M.S.A. Karunaratne, S.L. Ogden, S.D. Kenny, R.C. Thomson, A multicomponent diffusion model for prediction of microstructural evolution in coated Ni based superalloy systems, Mater. Sci. Technol. 25 (2009) 287-299.

[48] H. Chen, D.G. McCartney, Some aspects on modelling of the $\beta$-phase depletion behaviour under different oxide growth kinetics in HVOF CoNiCrAlY coatings, Surf. Coat. Technol. 313 (2017) 107-114.

[49] D. Toma, W. Brandl, U. Köster, Studies on the transient stage of oxidation of VPS and HVOF sprayed MCrAlY coatings, Surf. Coat. Technol. 120-121 (1999) 8-15. 
[50] W.R. Chen, X. Wu, B.R. Marple, D.R. Nagy, P.C. Patnaik, TGO growth behaviour in TBCs with APS and HVOF bond coats, Surf. Coat. Technol. 202 (2008) 2677-2683.

[51] H. Chen, T.H. Hyde, Use of multi-step loading small punch test to investigate the ductile-to-brittle transition behaviour of a thermally sprayed CoNiCrAlY coating, Mater. Sci. Eng. A 680 (2017) 203-209.

[52] S. Bose, High Temperature Coatings, Elsevier Butterworth-Heinemann, Oxford, 2007. [53] H. Chen, T.H. Hyde, K.T. Voisey, D.G. McCartney, Application of small punch creep testing to a thermally sprayed CoNiCrAlY bond coat, Mater. Sci. Eng. A 585 (2013) 205-213. [54] H. Chen, Microstructure characterisation of un-melted particles in a plasma sprayed CoNiCrAlY coating, Mater. Charact. 136 (2018) 444-451.

[55] S.V. Divinski, G. Reglitz, G. Wilde, Grain boundary self-diffusion in polycrystalline nickel of different purity levels, Acta Mater. 58 (2010) 386-395. 
Table 1

The compositions of MCrAIYs used for Thermo-Calc and DICTRA calculations with Y neglected.

\begin{tabular}{c|c|c|c|c|c}
\hline & \multicolumn{5}{|c}{ Elements } \\
\cline { 2 - 6 } & Co & Ni & Cr & Al & Y \\
\hline MCrAlY-8 & Bal. & 32 & 21 & 8 & 0.5 \\
\hline MCrAlY-10 & Bal. & 32 & 21 & 10 & 0.5 \\
\hline MCrAlY-12 & Bal. & 32 & 21 & 12 & 0.5 \\
\hline
\end{tabular}


Table 2

The parameters for the oxide growth model and time-dependent oxide growth rate model.

\begin{tabular}{c|c|c|c|c}
\hline \multirow{2}{*}{ Parameters } & $\mathrm{Q}$ & $\mathrm{T}_{0}$ & $\mathrm{n}$ & $\mathrm{T}$ \\
\cline { 2 - 5 } & $27,777.4 \mathrm{~K}$ & $2423.7 \mathrm{~K}$ & 0.332 & $1273-1473 \mathrm{~K}$ \\
\hline
\end{tabular}


Table 3

The composition of the minor $\sigma$ phase in MCrAlY-12 alloy at $1000{ }^{\circ} \mathrm{C}$.

\begin{tabular}{c|c|c|c|c}
\hline \multirow{2}{*}{} & \multicolumn{4}{|c}{ Elements } \\
\cline { 2 - 5 } & $\mathrm{Co}$ & $\mathrm{Ni}$ & $\mathrm{Cr}$ & $\mathrm{Al}$ \\
\hline$\sigma$ & 36.6 & 5.6 & 57.1 & 0.7 \\
\hline
\end{tabular}


Table 4

The effective diffusion coefficient of the $\beta$-phase depletion in MCrAIY8, MCrAIY-10 and MCrAIY-12 at different temperatures.

\begin{tabular}{c|c|c|c}
\hline \multirow{2}{*}{} & \multicolumn{2}{|c}{ Effective diffusion coefficient, $\mathrm{D}_{\text {eff }}\left(\mathrm{m}^{2} / \mathrm{s}\right)$} \\
\hline & $\mathrm{MCrAlY}-8$ & MCrAlY-10 & MCrAlY-12 \\
\hline $1000^{\circ} \mathrm{C}$ & $4.33 \times 10^{-16}$ & $1.93 \times 10^{-16}$ & $1.06 \times 10^{-16}$ \\
\hline $1100^{\circ} \mathrm{C}$ & $2.44 \times 10^{-15}$ & $8.70 \times 10^{-16}$ & $4.24 \times 10^{-16}$ \\
\hline $1200^{\circ} \mathrm{C}$ & $1.46 \times 10^{-14}$ & $3.42 \times 10^{-15}$ & $1.38 \times 10^{-15}$ \\
\hline
\end{tabular}




\section{Figure Captions}

Fig. 1. The schematic diagram of the DICTRA $\beta$-phase depletion model set up and node distribution.

Fig. 2. Plots of $\mathrm{Al}$ flux functions at $1000{ }^{\circ} \mathrm{C}, 1100^{\circ} \mathrm{C}$ and $1200^{\circ} \mathrm{C}$. The starting $\mathrm{Al}$ flux at each temperature is also highlighted assuming $1 \mu \mathrm{m} \mathrm{Al}{ }_{2} \mathrm{O}_{3}$ has formed: $1.6 \times 10^{-5} \mathrm{~mol} / \mathrm{m}^{2} / \mathrm{s}$ at $1200{ }^{\circ} \mathrm{C}, 4.0 \times 10^{-6} \mathrm{~mol} / \mathrm{m}^{2} / \mathrm{s}$ at $1100{ }^{\circ} \mathrm{C}$ and $1.7 \times 10^{-7} \mathrm{~mol} / \mathrm{m}^{2} / \mathrm{s}$ at $1000{ }^{\circ} \mathrm{C}$.

Fig. 3. Plots of phase fraction against temperature for (a) MCrAlY-8, (b) MCrAlY-10 and (c) MCrAlY-12.

Fig. 4. (a) $\gamma$-phase fraction and (b) $\beta$-phase fraction against Al content at different temperatures.

Fig. 5. (a) $\gamma$-phase and (b) $\beta$-phase compositions in the MCrAlYs at different temperatures.

Fig. 6. Oxide growth behaviour according to Eq. (1) at $1000{ }^{\circ} \mathrm{C}, 1100{ }^{\circ} \mathrm{C}$ and $1200{ }^{\circ} \mathrm{C}$.

Fig. 7. Oxide growth rate according to Eq. (2) at $1000{ }^{\circ} \mathrm{C}, 1100{ }^{\circ} \mathrm{C}$ and $1200{ }^{\circ} \mathrm{C}$.

Fig. 8. The evolution of phase fraction against distance for MCrAlY-8 at different temperatures: (a) $1000{ }^{\circ} \mathrm{C}$, (b) $1100{ }^{\circ} \mathrm{C}$ and (c) $1200{ }^{\circ} \mathrm{C}$.

Fig. 9. The evolution of phase fraction against distance for MCrAlY-10 at different temperatures: (a) $1000{ }^{\circ} \mathrm{C}$, (b) $1100^{\circ} \mathrm{C}$ and (c) $1200^{\circ} \mathrm{C}$.

Fig. 10. The evolution of phase fraction against distance for MCrAlY-12 at different temperatures: (a) $1000{ }^{\circ} \mathrm{C}$, (b) $1100{ }^{\circ} \mathrm{C}$ and (c) $1200{ }^{\circ} \mathrm{C}$.

Fig. 11. The element profiles after $100 \mathrm{~h}$ oxidation for (a) MCrAlY-8, (b) MCrAlY-10 and (c) MCrAlY-12 at different temperatures.

Fig. 12. Summary of the $\beta$-phase depletion against oxidation time in (a) MCrAlY-8, (b) MCrAlY-10 and (c) MCrAlY-12 at different temperatures. The experimentally measured $\beta$ phase depletion zone from MCrAlY-8 is included in (a).

Fig. 13. Microstructures of MCrAlY-8 after annealing for $100 \mathrm{~h}$ at (a) $1000^{\circ} \mathrm{C}$, (b) $1100{ }^{\circ} \mathrm{C}$ and (c) $1200{ }^{\circ} \mathrm{C}$.

Fig. 14. The comparison between the converted and calculated $\beta$-phase mass fraction for MCrAlY-8 alloy.

Fig. 15. Microstructure of MCrAlY-8 after oxidation for $100 \mathrm{~h}$ at (a) $1000{ }^{\circ} \mathrm{C}$, (b) $1100{ }^{\circ} \mathrm{C}$, (c) $1200{ }^{\circ} \mathrm{C}$ and (d) the XRD patterns of MCrAlY-8 after exposure at these conditions. 
ig. 1

flick here to download high resolution image

\section{MCrAIY Coating Alloy}

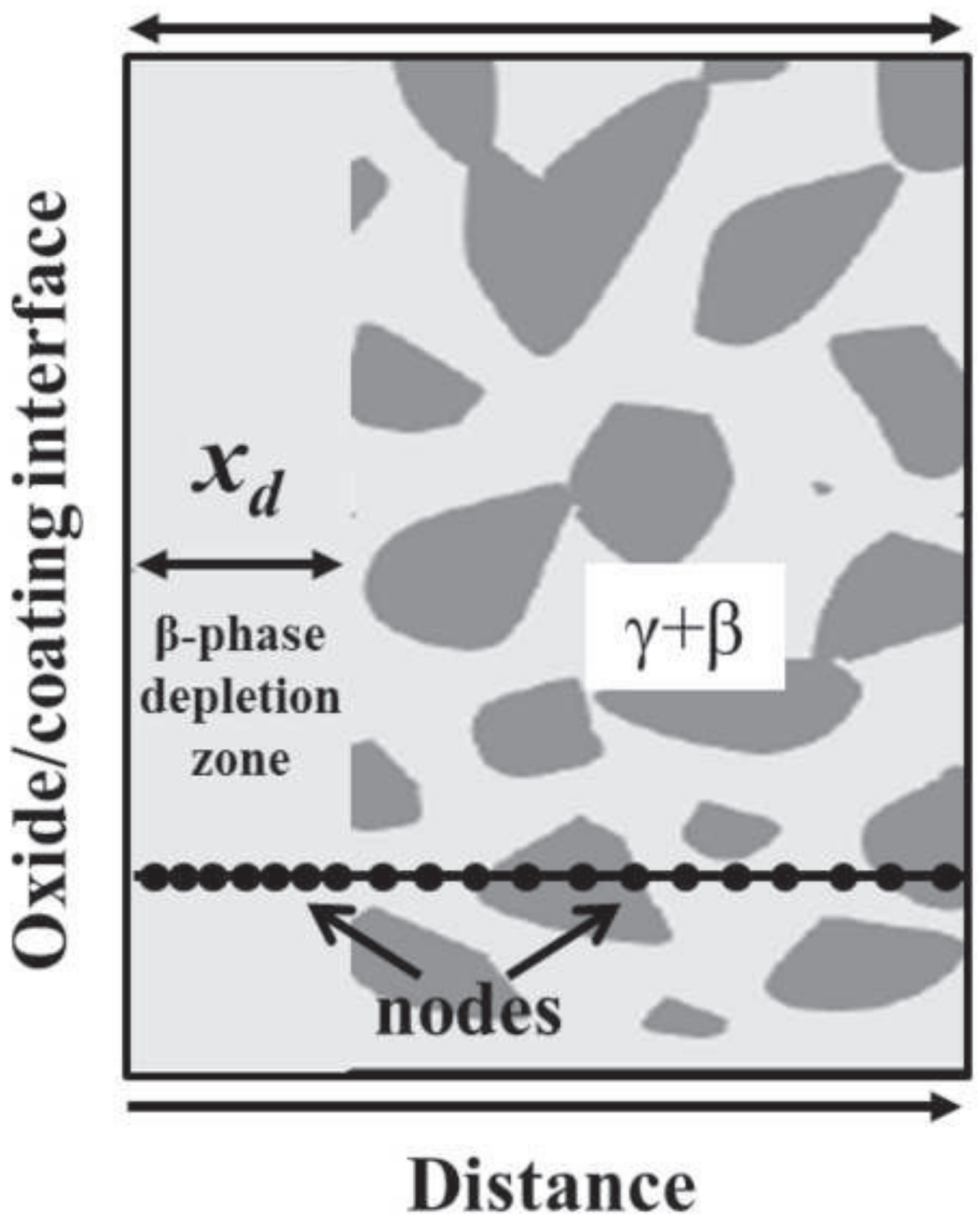




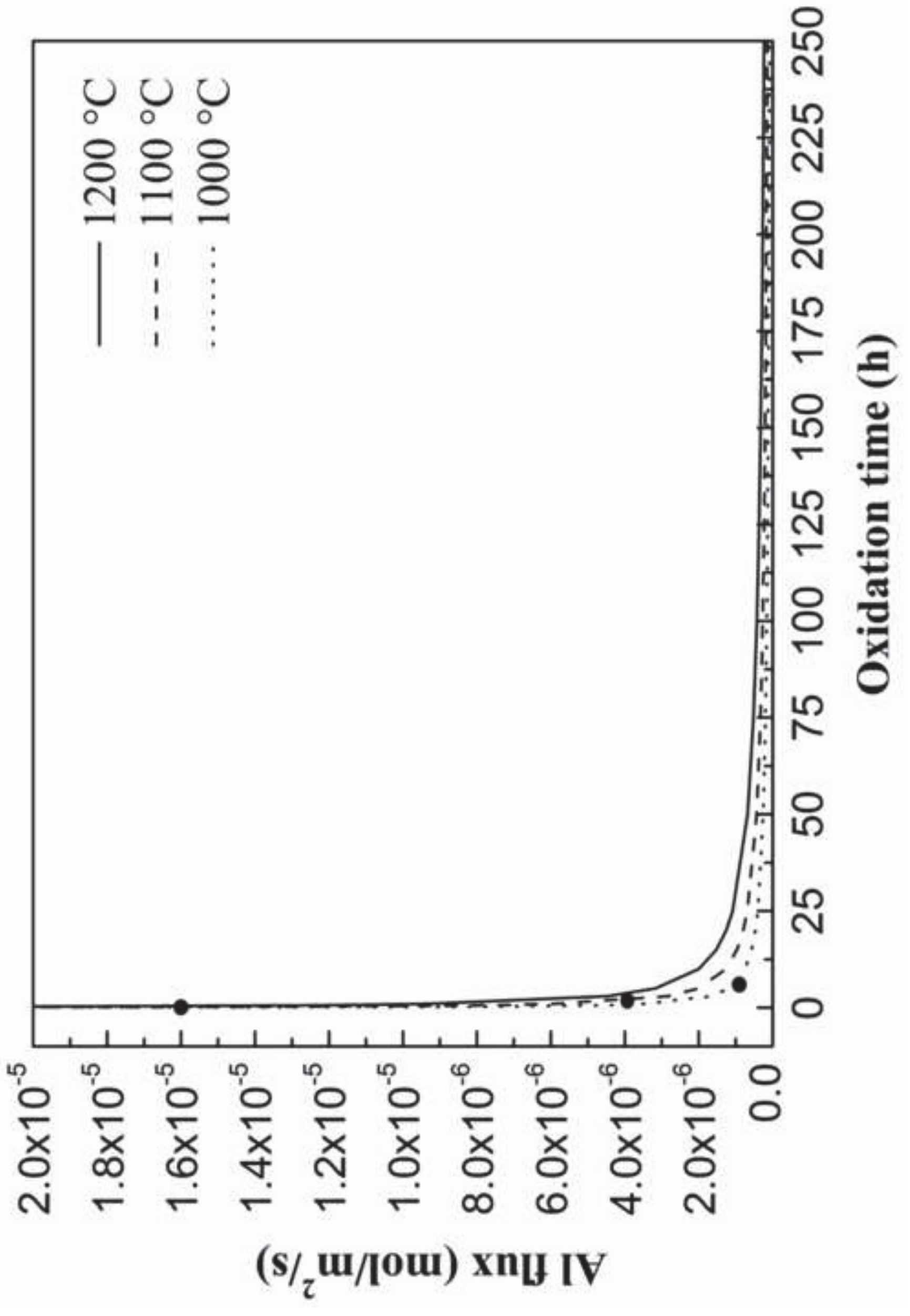



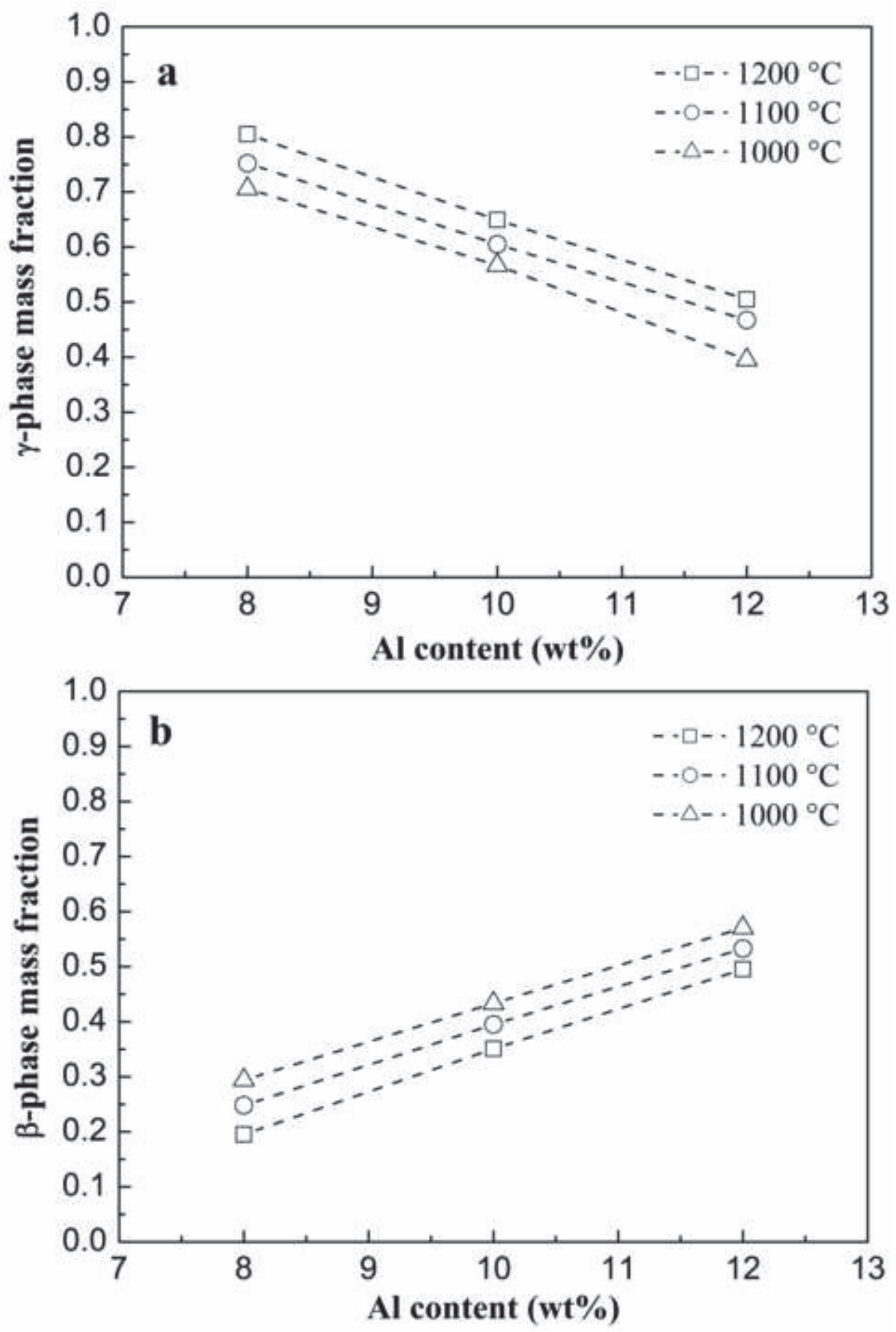


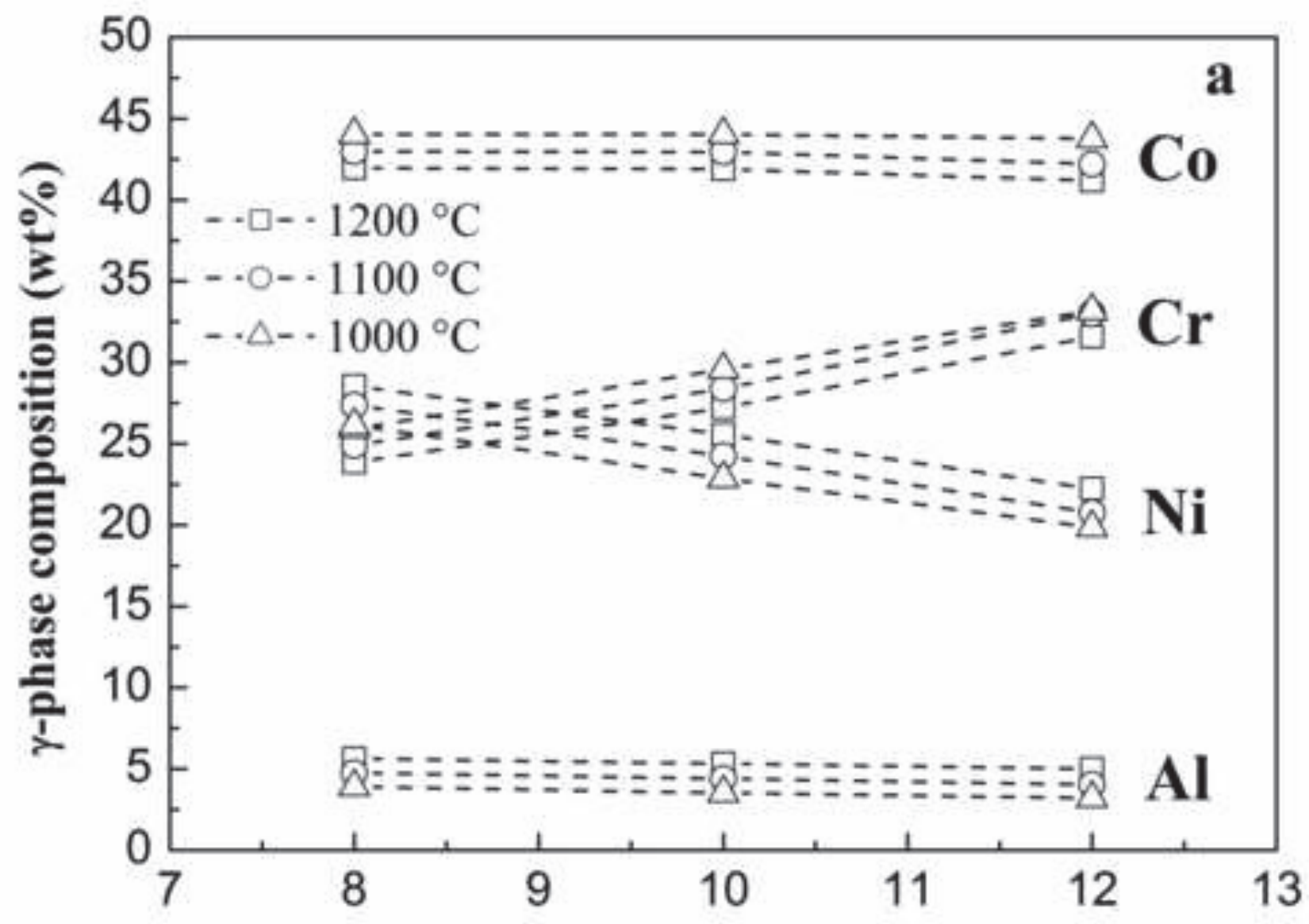

Al content (wt \%)

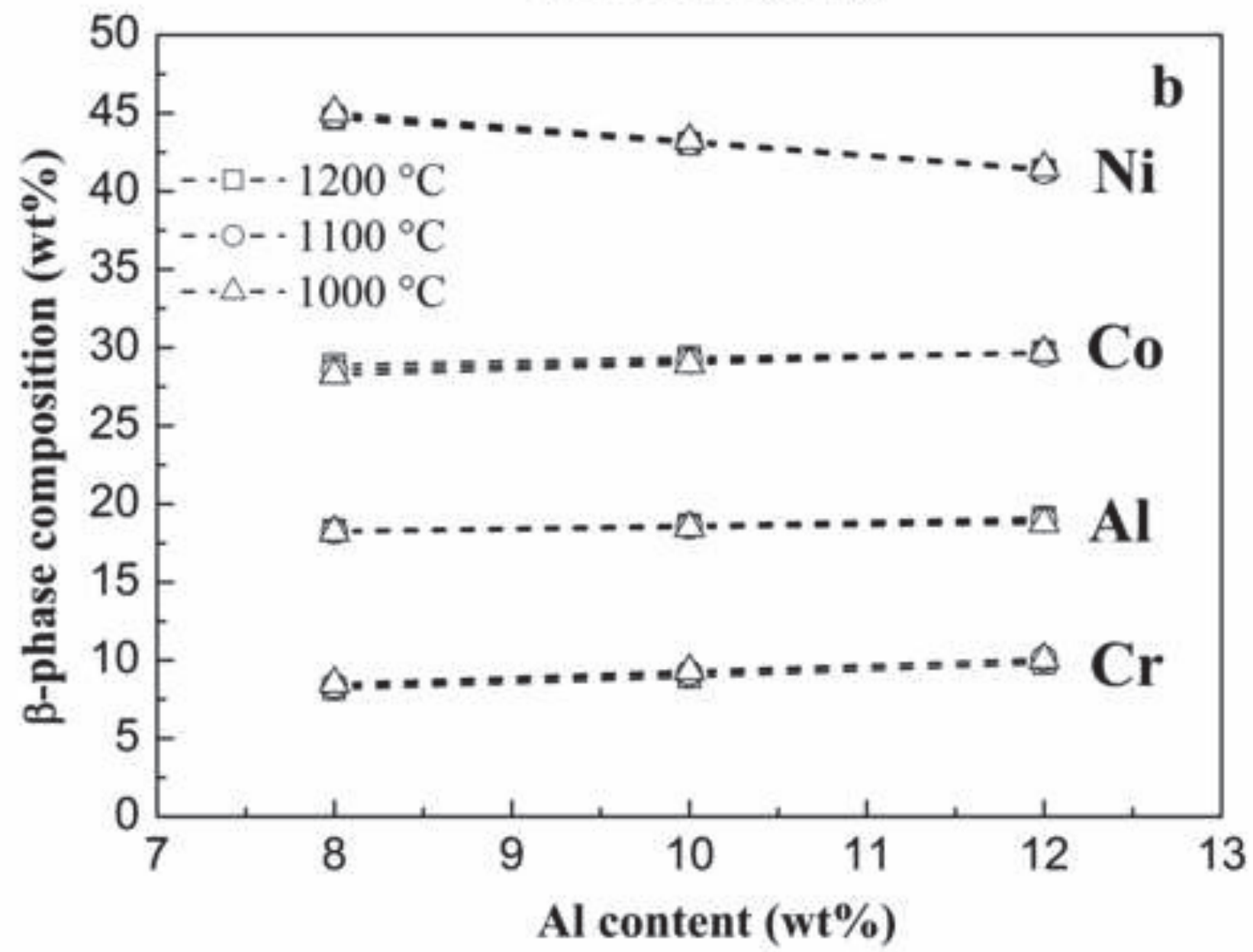




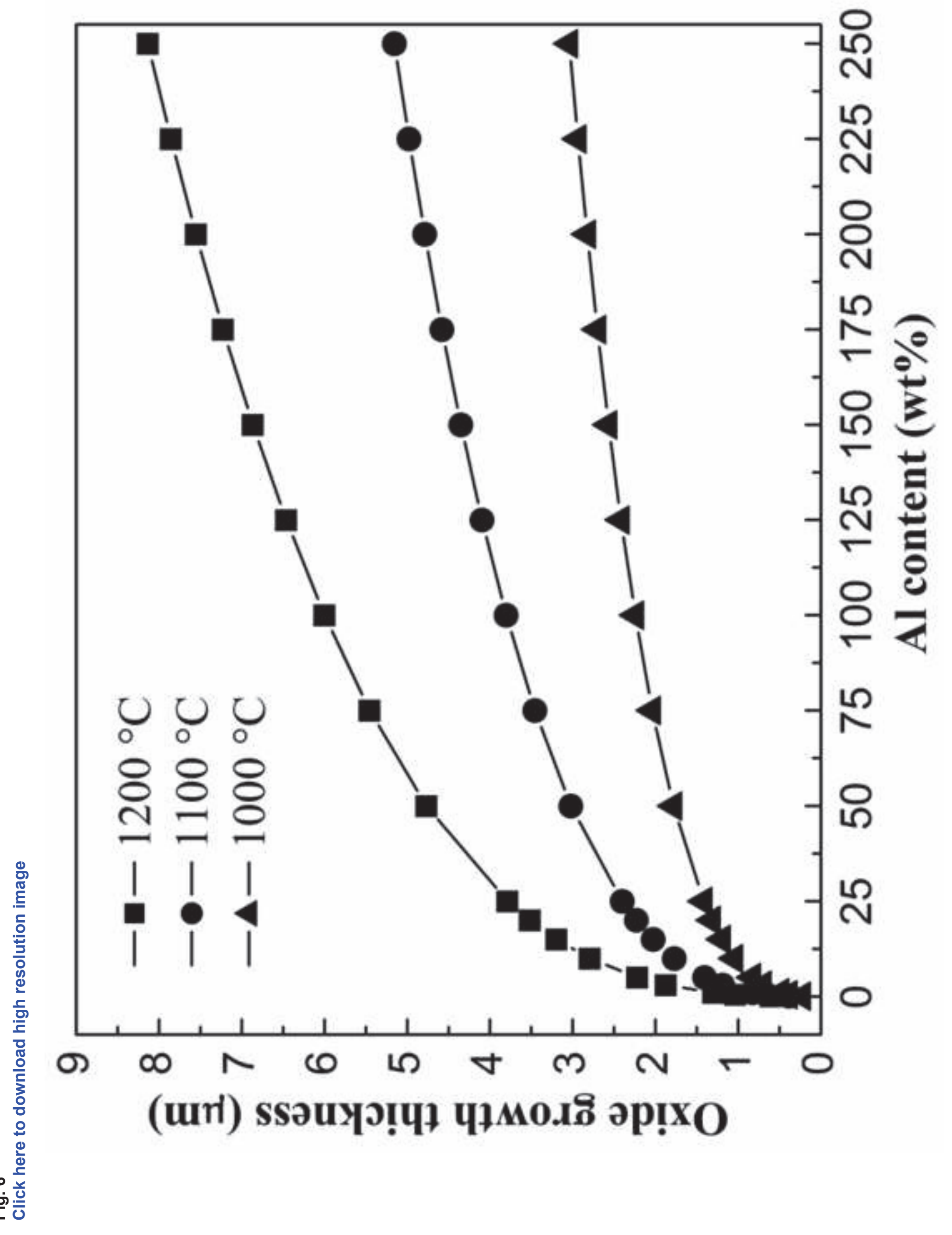




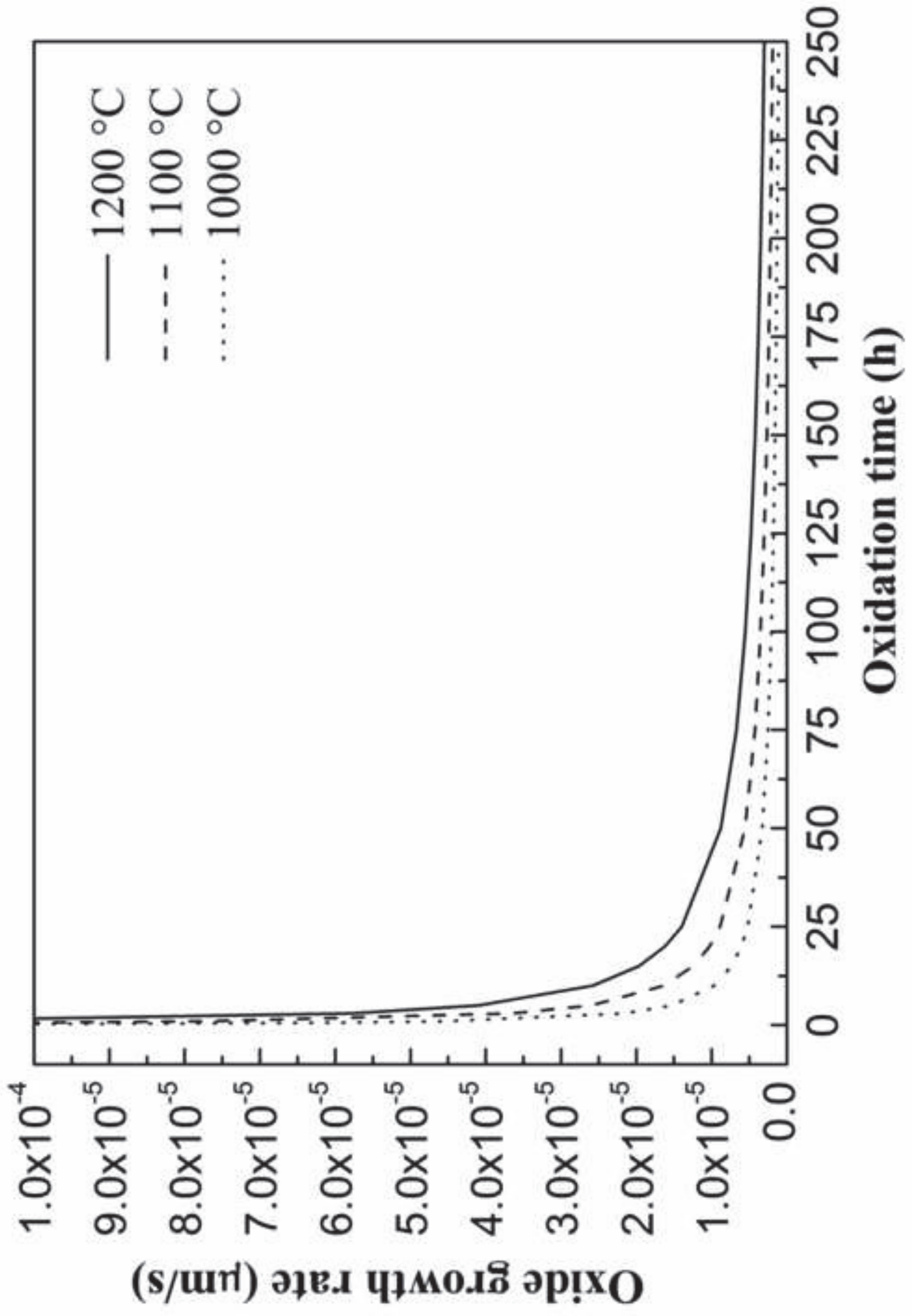


ig. 8

lick here to download high resolution image
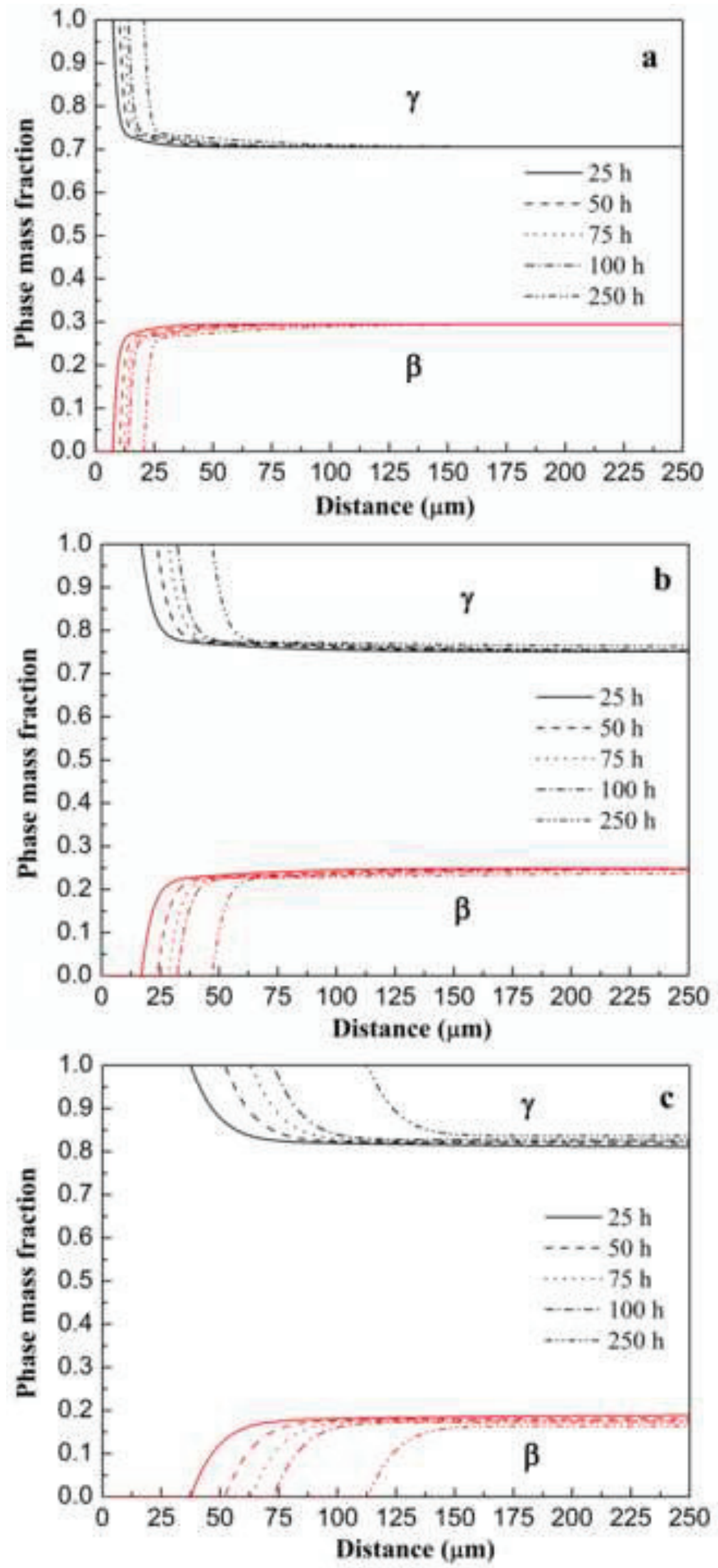

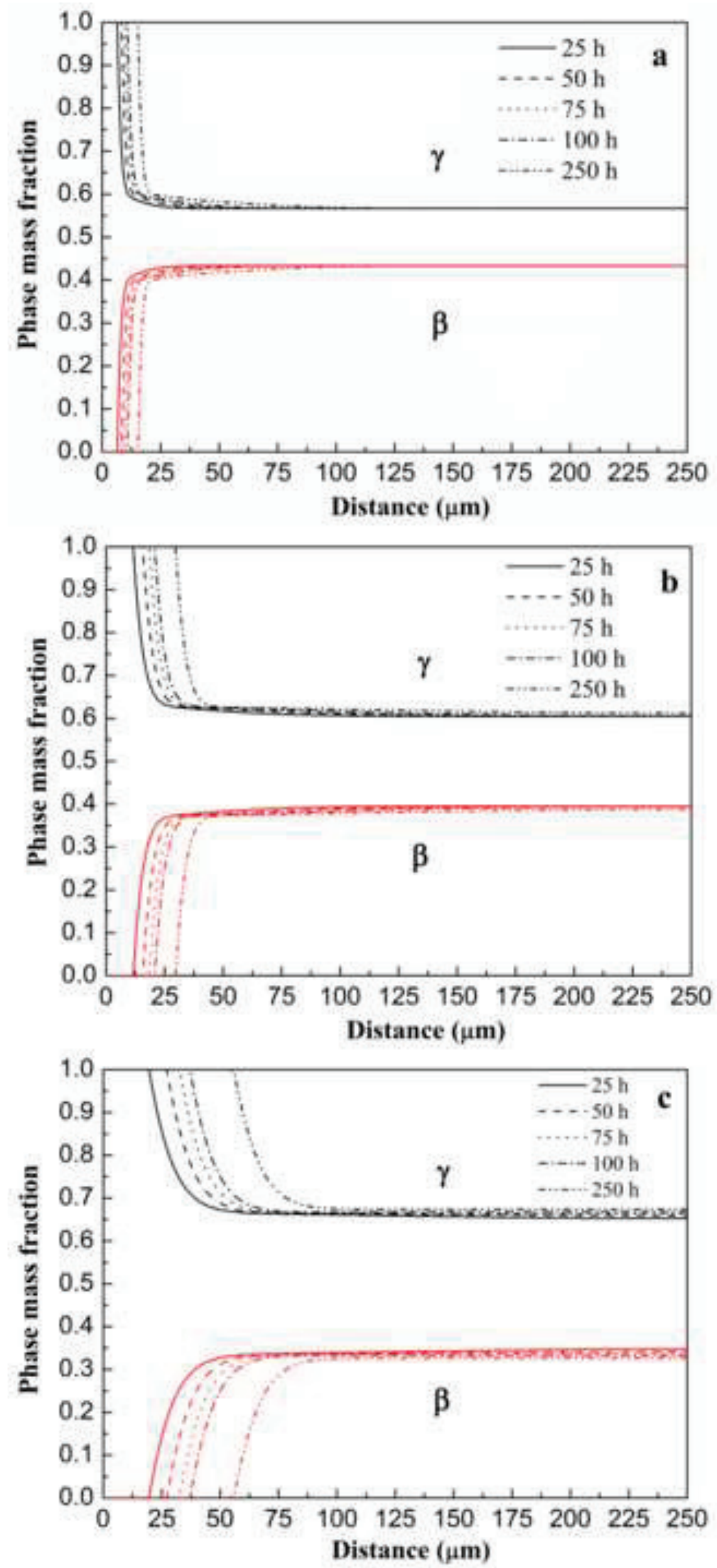

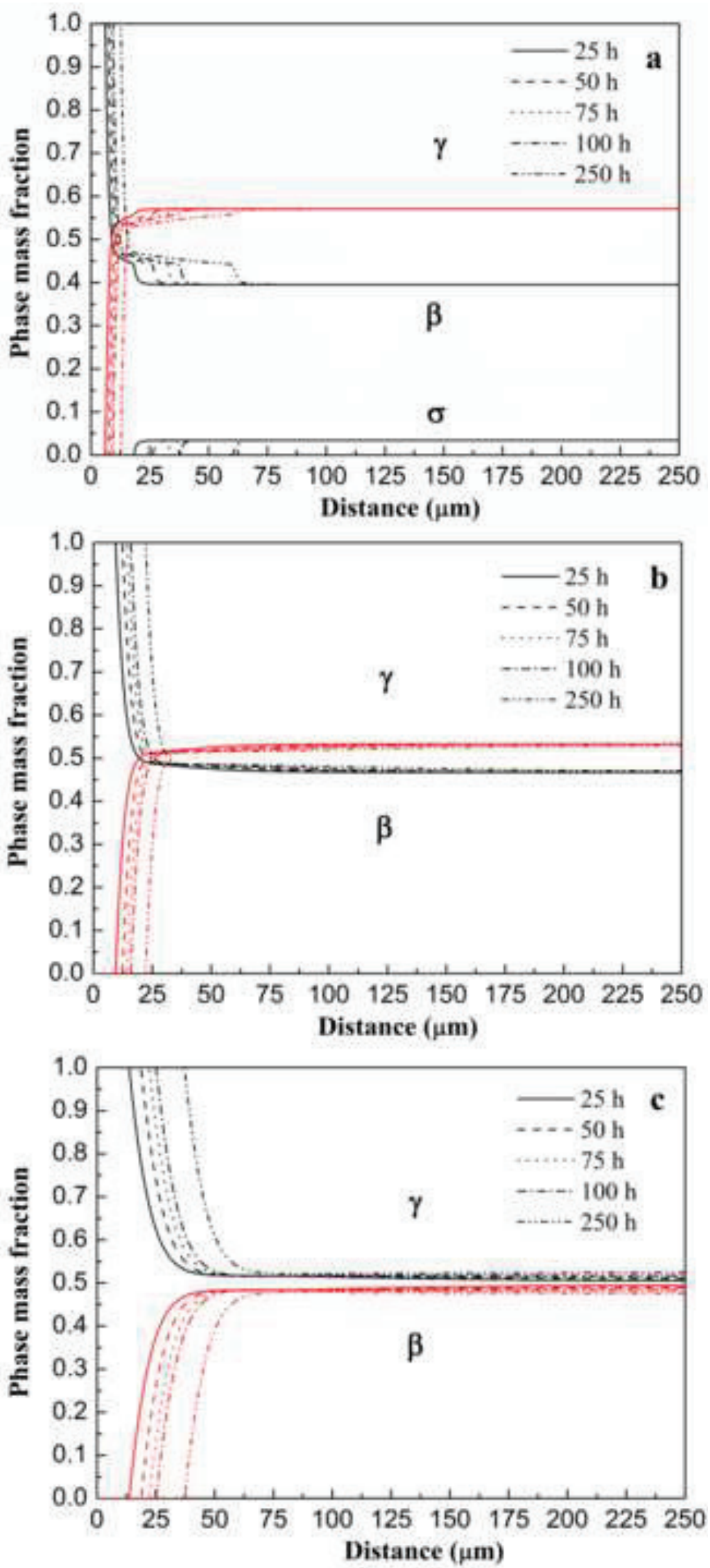

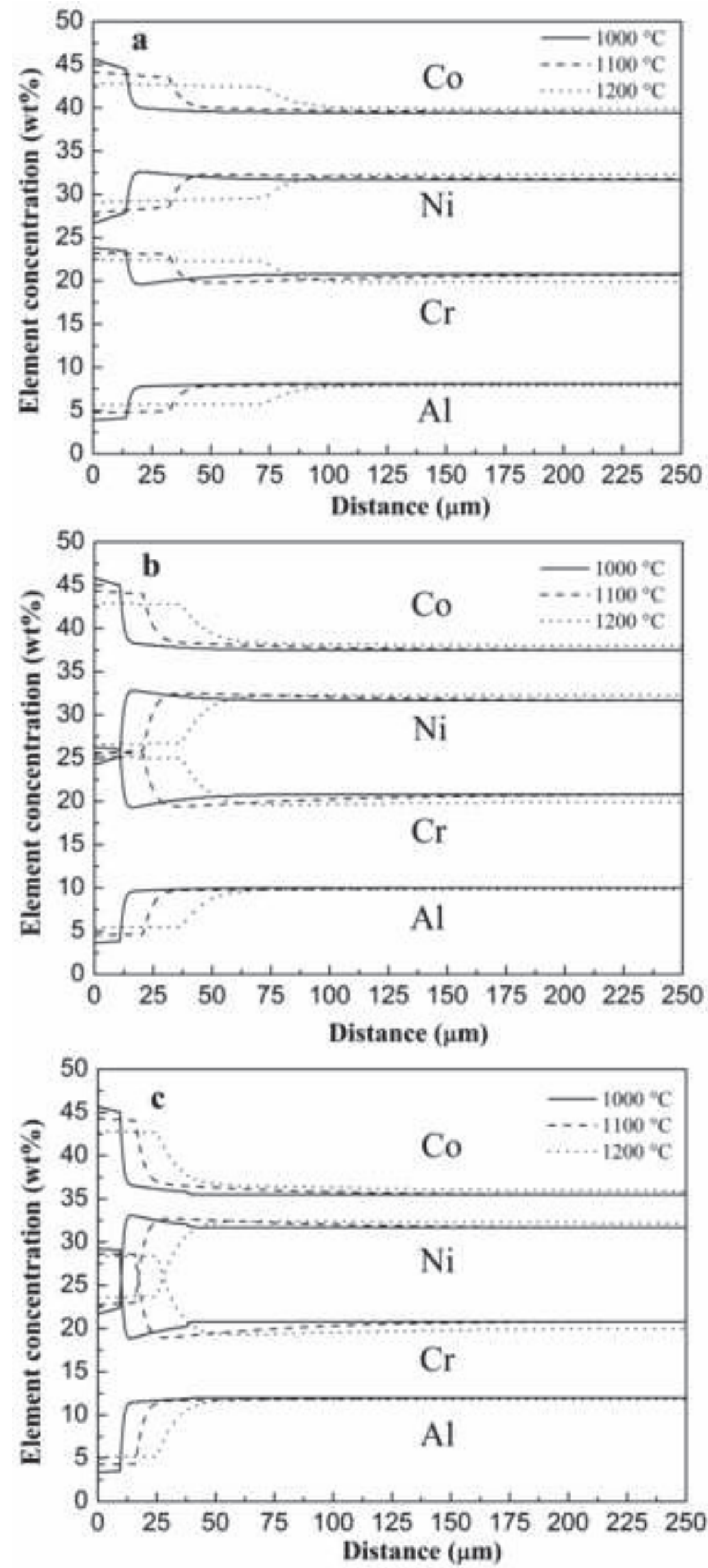

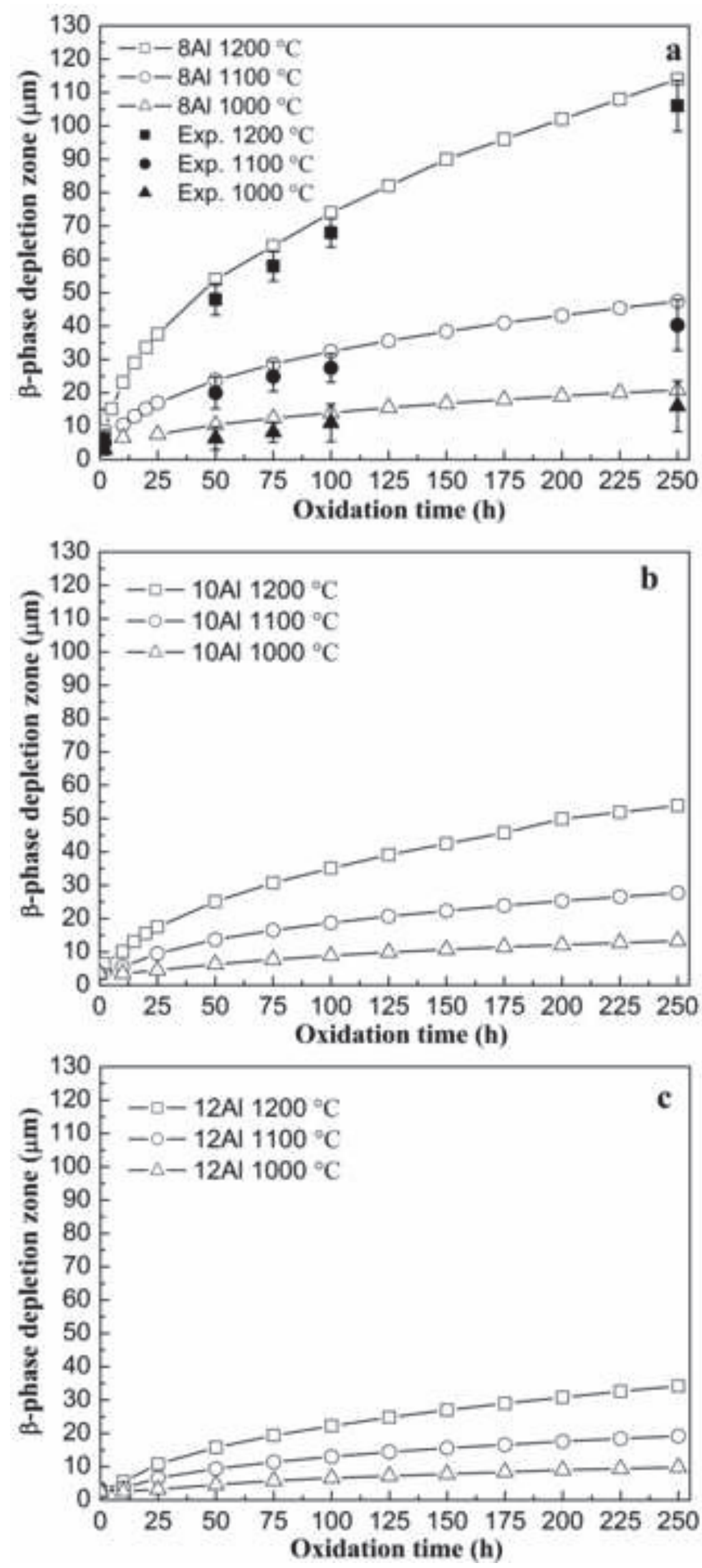


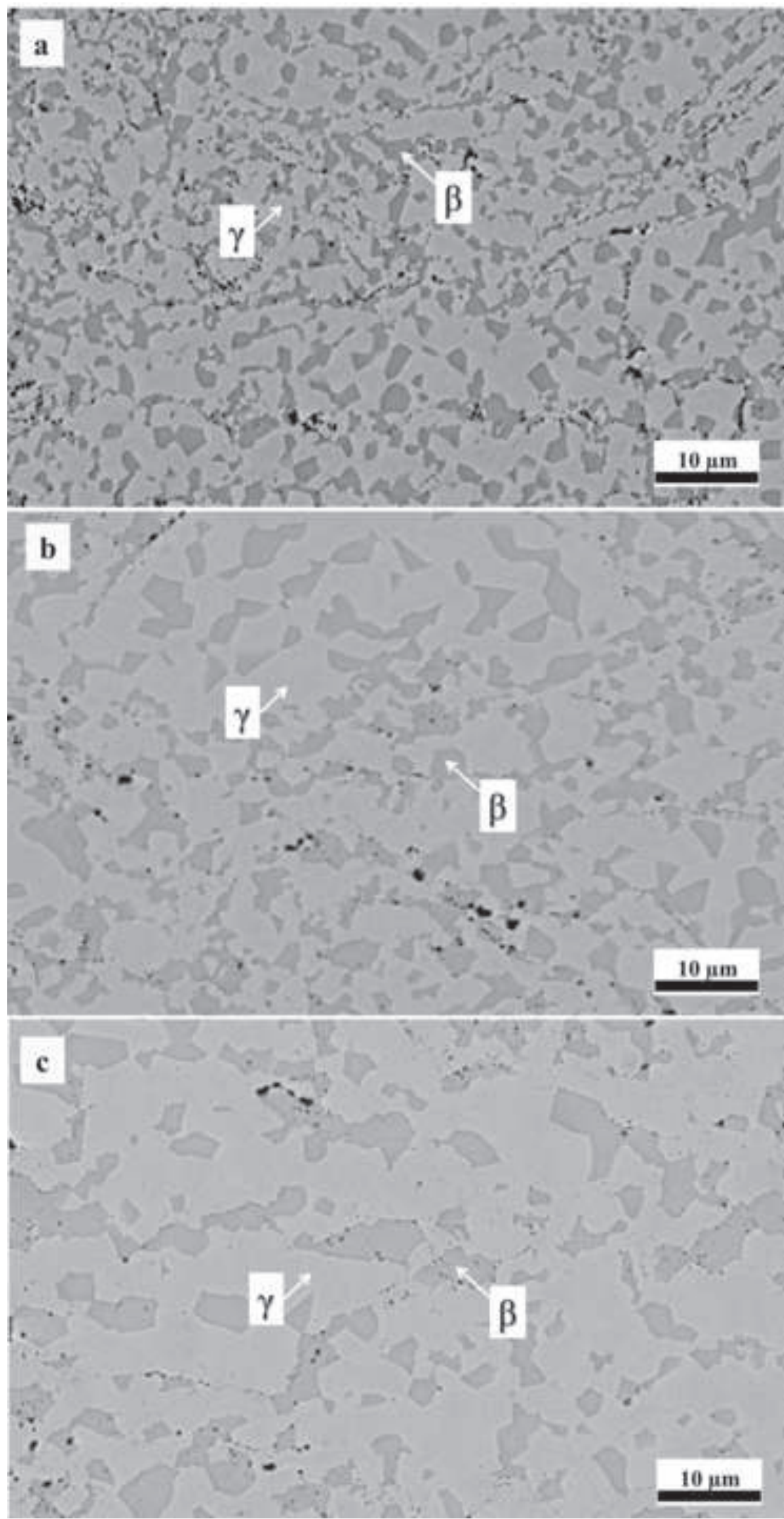




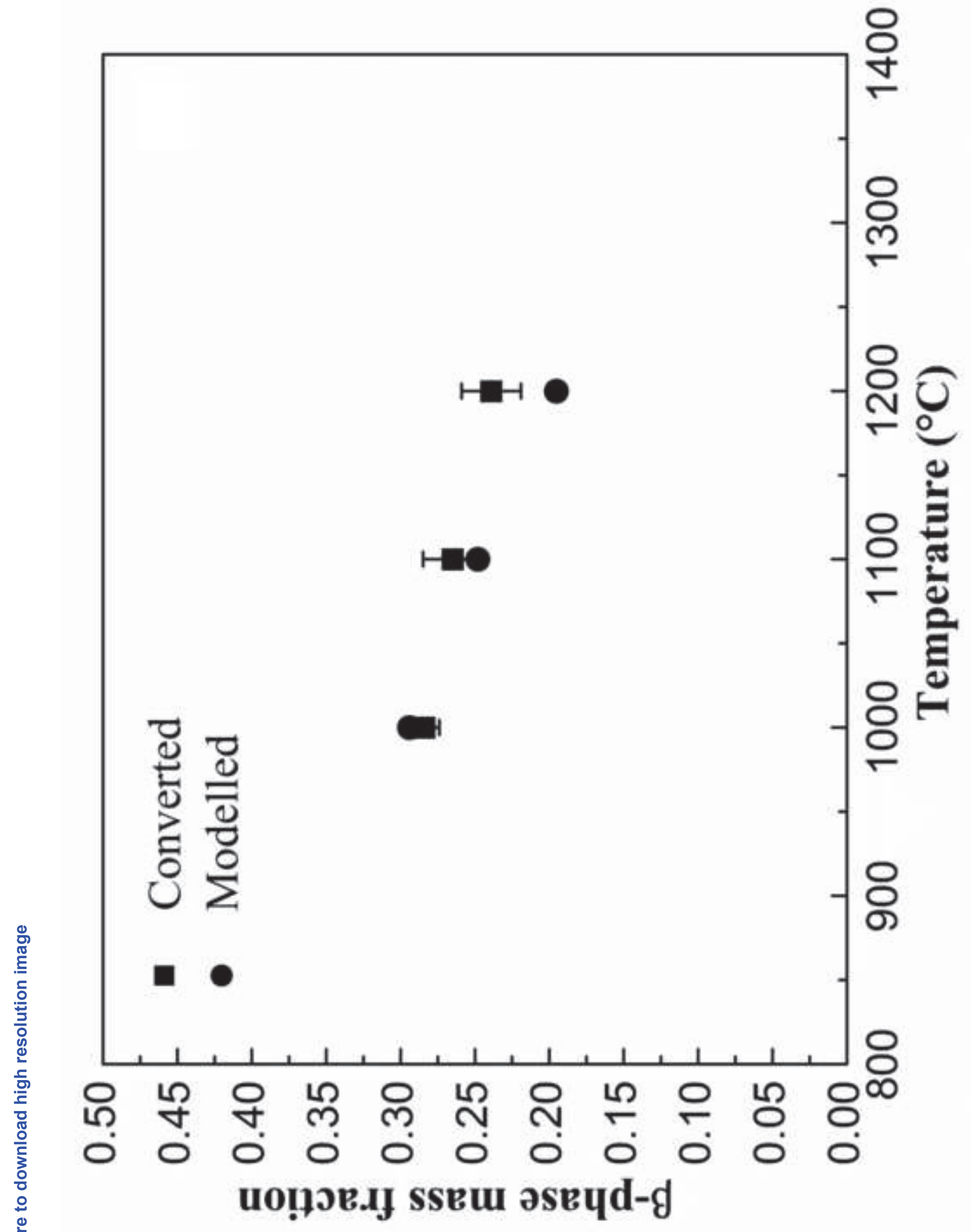



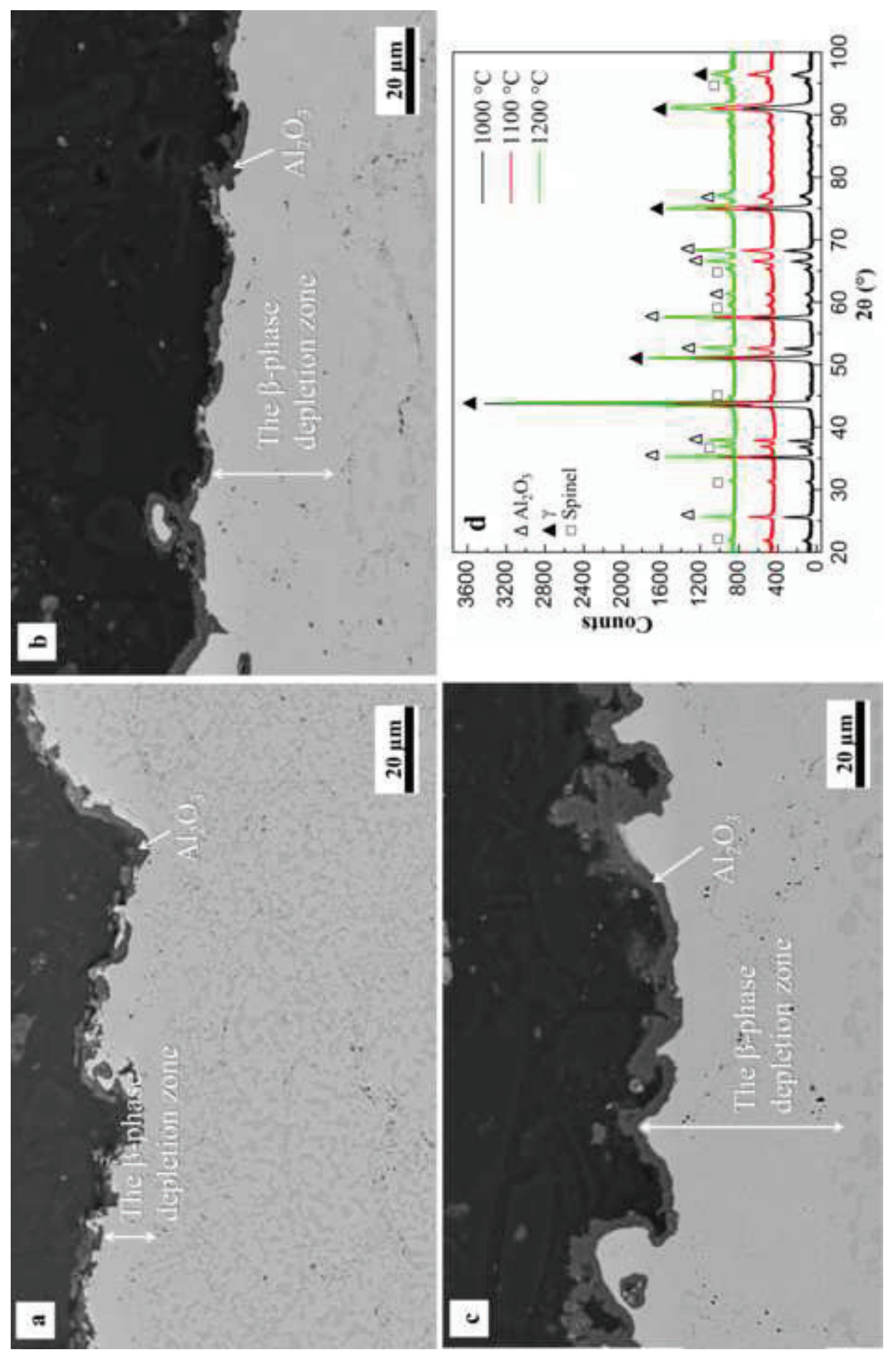